\title{
Wnt-7a Induces Presynaptic Colocalization of $\alpha 7$-Nicotinic Acetylcholine Receptors and Adenomatous Polyposis Coli in Hippocampal Neurons
}

\author{
Ginny G. Farías, ${ }^{1}$ Ana S. Vallés, ${ }^{2}$ Marcela Colombres, ${ }^{1}$ Juan A. Godoy, ${ }^{1}$ Enrique M. Toledo, ${ }^{1}$ Ronald J. Lukas, ${ }^{3}$ \\ Francisco J. Barrantes, ${ }^{2}$ and Nibaldo C. Inestrosa ${ }^{1}$ \\ ${ }^{1}$ Centro de Regulación Celular y Patología “Joaquin V. Luco," Millennium Institute for Fundamental and Applied Biology, Facultad de Ciencias Biológicas, \\ Pontificia Universidad Católica de Chile, 8331010 Santiago, Chile, ${ }^{2}$ Instituto de Investigaciones Bioquímicas de Bahía Blanca, 8000 Bahía Blanca, Argentina, \\ and ${ }^{3}$ Division of Neurobiology, Barrow Neurological Institute, Phoenix, Arizona 85013
}

\begin{abstract}
Nicotinic acetylcholine receptors (nAChRs) contribute significantly to hippocampal function. $\alpha 7$-nAChRs are present in presynaptic sites in hippocampal neurons and may influence transmitter release, but the factors that determine their presynaptic localization are unknown. We report here that $W n t-7 a$, a ligand active in the canonical $W n t$ signaling pathway, induces dissociation of the adenomatous polyposis coli (APC) protein from the $\beta$-catenin cytoplasmic complex and the interaction of APC with $\alpha 7$-nAChRs in hippocampal neurons. Interestingly, Wnt-7a induces the relocalization of APC to membranes, clustering of APC in neurites, and coclustering of APC with different, presynaptic protein markers. Wnt-7a also increases the number and size of coclusters of $\alpha 7$-nAChRs and APC in presynaptic terminals. These short-term changes in $\alpha 7$-nAChRs occur in the few minutes after ligand exposure and involve translocation to the plasma membrane without affecting total receptor levels. Longer-term exposure to Wnt-7a increases nAChR $\alpha 7$ subunit levels in an APC-independent manner and increases clusters of $\alpha 7$-nAChRs in neurites via an APC-dependent process. Together, these results demonstrate that stimulation through the canonical Wnt pathway regulates the presynaptic localization of APC and $\alpha 7$-nAChRs with APC serving as an intermediary in the $\alpha 7$-nAChR relocalization process. Modulation by Wnt signaling may be essential for $\alpha 7$-nAChR expression and function in synapses.
\end{abstract}

Key words: nAChR; APC; synapse; Wnt; Wnt target gene; neurons

\section{Introduction}

In the CNS, $\alpha 7$-nicotinic acetylcholine receptors ( $\alpha 7$-nAChRs) are involved in several aspects of brain function. $\alpha 7$-nAChRs affect neuronal development (Role and Berg, 1996), learning, and memory (Levin and Simon, 1998). Because of their high permeability to calcium ions, $\alpha 7$-nAChRs influence synaptic efficacy and induction of long-term potentiation (Vernino et al., 1992). $\alpha 7$-nAChRs have been implicated in a wide variety of neuronal diseases, including schizophrenia (Freedman et al., 2003), bipolar disorder, Parkinson's disease, and Alzheimer's disease (AD) (Banerjee et al., 2000; Kem, 2000).

\footnotetext{
Received May 2, 2006; revised March 19, 2007; accepted March 24, 2007.

This work was supported by grants from Fondo de Investigación Avanzada en Áreas Prioritarias (13980001) and the Millennium Institute for Fundamental and Applied Biology (N.C.I.); by predoctoral fellowships from Comisión Nacional de Investigación Científica y Tecnológica (CONICYT) (G.G.F., M.C.) and from Consejo Nacional de Investigaciones Científicas y Técnicas (CONICET) (A.S.V); by grants from CONICET, Fondo Nacional para las Ciencias y la Tecnología, and Universidad Nacional del Sur (F.J.B.); by a grant from Secretaría de Ciencia y Tecnología-CONICYT (N.C.I., F.J.B.); by National Institutes of Health Grants DA015389 and NS040417; by Arizona Biomedical Research Commission Grant 9615; and by the Barrow Neurological Foundation (R.J.L.). We thank Drs. Patricia Salinas, Jeremy Nathans, and Randall Moon for their kind gifts of different constructs.

Correspondence should be addressed to Dr. Nibaldo C. Inestrosa, Centro de Regulación Celular y Patología "Joaquin V. Luco" Biomedical Center, Pontificia Universidad Católica de Chile, P.O. Box 114-D, Santiago, Chile. E-mail: ninestr@bio.puc.cl.

DOI:10.1523/JNEUROSCI.3934-06.2007

Copyright $\odot 2007$ Society for Neuroscience $\quad$ 0270-6474/07/275313-13\$15.00/0
}

In hippocampal neurons, $\alpha 7$-nAChRs can be found at presynaptic terminals, at which they colocalize with synaptotagmin, thus explaining their role in neurotransmitter release at both GABAergic and glutamatergic nerve terminals (Gray et al., 1996; Radcliffe and Dani, 1998; Alkondon and Albuquerque, 2001; Kawai et al., 2002; Zago et al., 2006). The factors that control $\alpha 7$-nAChR distribution and influence its presynaptic localization are still unknown.

Canonical Wnt signaling is essential for neuronal development and the maintenance of the developing nervous system (Patapoutian and Reichardt, 2000), and it has recently been implicated in adult hippocampal neurogenesis (Lie et al., 2005). During the last several years, work in our laboratory has demonstrated that the activation of Wnt signaling prevents amyloid- $\beta$ $(\mathrm{A} \beta)$ neurotoxicity in hippocampal neurons (Garrido et al., 2002; De Ferrari et al., 2003; Alvarez et al., 2004; Quintanilla et al., 2005).

Activation of Wnt signaling by a specific, canonical Wnt ligand involves dissociation of $\beta$-catenin from a complex also containing axin, casein kinase, glycogen synthase kinase- $3 \beta$ (GSK-3 $\beta$ ) and the adenomatous polyposis coli (APC) protein. In the absence of Wnt activation, $\beta$-catenin in the complex is phosphorylated, ubiquitinated, and degraded in the proteasome (Aberle et al., 1997). However, $W n t$ ligand action promotes $\beta$-catenin dis- 
sociation from the destruction complex, thus enhancing $\beta$-catenin stabilization, and translocation of $\beta$-catenin to the nucleus, in which it interacts with Tcf/LEF transcription factors to activate the expression of Wnt target genes (Nusse and Varmus, 1992). The latter include c-myc, engrailed-2, cyclooxygenase-2, neurogenin-1, and other genes (Moon et al., 2004).

APC, a component of the $\beta$-catenin degradation complex, has been suggested to play a role in synapses. In particular, skeletal muscle APC is required for agrin-induced AChR clustering at the neuromuscular junction (Wang et al., 2003), and APC maintains the surface levels as well as the clustering of postsynaptic $\alpha 3^{*}$ nAChRs in chick ciliary ganglion neurons (Temburni et al., 2004). In hippocampal neurons, APC is expressed at high levels in the cytoplasm, in which it interacts with $\beta$-catenin (Brakeman et al., 1999). However, APC also has been found at presynaptic sites, at which it colocalizes with synaptotagmin, a synaptic vesicle protein (Matsumine et al., 1996).

Function(s) of APC in presynaptic sites and mechanisms by which $\alpha 7$-nAChRs localize to presynaptic sites are unknown. Here, we investigated roles of Wnt canonical signaling in the localization of APC in presynaptic sites and in the interaction of APC with $\alpha 7$-nAChRs.

\section{Materials and Methods}

Constructs. Control and mouse APC small interfering RNA (siRNA) were from Santa Cruz Biotechnology (Santa Cruz, CA), green fluorescent protein (GFP) was from Clontech (Mountain View, CA); HA-Wnt-7a was a gift from Dr. P. Salinas (University College London, London, UK), and HA-sFRP was a gift from Dr. Jeremy Nathans (Johns Hopkins University School of Medicine, Baltimore, MD).

Hippocampal neuronal cultures and transfection. Hippocampal neurons were obtained from Sprague Dawley rats at embryonic day 18. Hippocampi were dissected, and primary cultures were prepared as described previously (Cáceres et al., 1984; Farías et al., 2004) and maintained in DMEM supplemented with $10 \%$ horse serum for $2 \mathrm{~h}$. The culture medium was then substituted with Neurobasal media supplemented with B27, $100 \mu \mathrm{g} / \mathrm{ml}$ streptomycin, and $100 \mathrm{U} / \mathrm{ml}$ penicillin. Cells were treated for $24 \mathrm{~h}$ with $2 \mu \mathrm{M}$ 1- $\beta$-D-arabinofuranosylcytosine (AraC) on day 3 to reduce the number of proliferating non-neuronal cells. Experiments were performed on day 14 in the presence or absence of different Wnt-7a or other entities. For transfection using GFP or siRNA constructs, cultured hippocampal neurons from C57BL mice at embryonic day 18 were prepared as for rat hippocampal cultures. Transfection was performed using the calcium phosphate method for neurons as described previously (Kohrmann et al., 1999) with some modifications. Hippocampal neurons were transfected on day 10 in vitro, and experiments were performed beginning on day 12 in vitro and involving up to $24 \mathrm{~h}$ of exposure to medium lacking or containing Wnt-7a.

Cell line culture. Human embryonic kidney 293 (HEK-293) cells were maintained in DMEM supplemented with $10 \%$ fetal calf serum (Invitrogen, Carlsbad, CA), $100 \mu \mathrm{g} / \mathrm{ml}$ streptomycin, and $100 \mathrm{U} / \mathrm{ml}$ penicillin. In initial studies, wild-type or transfected SH-EP1 cells expressing human $\alpha 7$-nAChRs were studied after being maintained according to previous descriptions (Zhao et al., 2003)

Conditioned medium containing Wnt ligands. To generate secreted Wnt ligands, HEK-293 cells were transiently transfected by calcium phosphate precipitation (Conroy and Berg, 1998) with constant and equal amounts of empty vector pcDNA or pcDNA containing sequences encoding Wnt-7a ligand. Transiently transfected HEK-293 cells also were used to produce soluble Frizzled receptor protein (sFRP) coupled to the sequence encoding a hemagglutinin tag. Transiently transfected HEK-293 cells were grown to $85 \%$ confluence and maintained in Neurobasal medium supplemented with $100 \mathrm{U} / \mathrm{ml}$ penicillin and $100 \mu \mathrm{g} / \mathrm{ml}$ streptomycin for $60 \mathrm{~h}$. Wnt-conditioned or control media or media containing sFRP (Ahmad-Annuar et al., 2006) were prepared as described previously (Hall et al., 2000; Rosso et al., 2004; Quintanilla et al., 2005; Seto and Bellen, 2006). Wht secretion was verified by Western blot using an anti-HA antibody (Millipore, Billerica, MA).

Cell fractionation and Western blot for detection of $\beta$-catenin and APC. Total protein was prepared from primary rat hippocampal neurons lysed in a buffer consisting of (in mM) 10 HEPES, pH 7.9, $1.5 \mathrm{MgCl} 2,10 \mathrm{KCl}$, and 1 DTT, supplemented with a protease inhibitor mixture (to achieve final concentrations of $1 \mathrm{~mm}$ PMSF, $2 \mu \mathrm{g} / \mathrm{ml}$ aprotinin, $2 \mu \mathrm{g} / \mathrm{ml}$ leupeptin, and $1 \mu \mathrm{g} / \mathrm{ml}$ pepstatin). Lysates were laid on ice for $30 \mathrm{~min}$ and centrifuged at $700 \times g$ for $5 \mathrm{~min}$ at $4^{\circ} \mathrm{C}$. Supernatants were centrifuged at $100,000 \times g$ for $1 \mathrm{~h}$ at $4^{\circ} \mathrm{C}$, and the pellets (equivalent to membrane or particulate fractions) were resuspended in a buffer containing $20 \mathrm{~mm}$ Tris-HCl, pH 7.5, 1 mm EDTA, 0.1\% Triton X-100, $0.15 \mathrm{~mm} \mathrm{NaCl}$, and the above protease inhibitor mixture. The supernatant (equivalent to the cytoplasmic fraction) was precipitated with methanol-chloroform. Equal amounts of protein were resolved using SDS-PAGE (6\% polyacrylamide), proteins were transferred to PVDF membranes, and immunoblotting was done using anti- $\beta$-catenin monoclonal or polyclonal antiAPC antibodies (Santa Cruz Biotechnology). Immune complexes were visualized by reaction with secondary antibodies linked to horseradish peroxidase followed by incubation with enhanced chemiluminescence reagents (Santa Cruz Biotechnology).

Immunoprecipitation assay. Treated neurons or control substances were washed twice in ice-cold PBS and lysed in a buffer "A" (25 mM HEPES, pH 7.4, $125 \mathrm{~mm} \mathrm{NaCl}, 25$ mм NaF, 1 mм EDTA, 1 mм EGTA, 1\% $\mathrm{NP}-40,1 \mathrm{~mm} \mathrm{NaVO}_{3}$, and the protease inhibitor mixture). Equal amounts of protein were precleared using protein A-Sepharose for $1 \mathrm{~h}$ at $4^{\circ} \mathrm{C}$ and then incubated with $3 \mu \mathrm{g}$ of antibody against the nAChR $\alpha 7$ subunit or APC. The immune complexes were affinity precipitated with protein A-Sepharose beads and washed six times with $25 \mathrm{~mm}$ HEPES buffer, pH 7.4, $10 \mathrm{~mm} \mathrm{MgCl}_{2}, 1 \mathrm{~mm} \mathrm{NaF}, 1 \% \mathrm{NP}-40$, and $1 \mathrm{~mm} \mathrm{NaVO}$. The immune complexes were then submitted to SDS-PAGE and analyzed by Western blots with mouse anti-APC, mouse anti- $\beta$-catenin, mouse anti-transferrin receptor (TF-R), mouse anti-tyrosine receptor kinase B (TrkB), goat anti-postsynaptic density protein-95 (PSD-95), or goat anti-vesicle-associated membrane protein 2 (VAMP-2; Santa Cruz Biotechnology).

$\alpha 7-n A C h R$ pull down. Total numbers of $\alpha 7$-nAChR from hippocampal neurons were obtained by washing cells twice in ice-cold PBS followed by lysis in radioimmunoprecipitation assay (RIPA) buffer $(50 \mathrm{~mm}$ Tris-Cl, $150 \mathrm{~mm} \mathrm{NaCl}, 1 \% \mathrm{NP}-40,0.5 \%$ sodium deoxycholate, and $0.1 \%$ SDS) supplemented with the protease inhibitor mixture described above. Lysates were incubated with $1 \mu \mathrm{g} / \mathrm{ml}$ biotinylated $\alpha$-bungarotoxin $(\alpha$ Btx) for $12 \mathrm{~h}$ at $4^{\circ} \mathrm{C}$ before addition of $40 \mu \mathrm{l}$ of streptavidin-Sepharose beads and incubation for $2 \mathrm{~h}$ at $4^{\circ} \mathrm{C}$. The complex was washed six times in a buffer containing $50 \mathrm{~mm}$ Tris- $\mathrm{HCl}, 150 \mathrm{~mm} \mathrm{NaCl}$, and $1 \%$ Triton $\mathrm{X}-100, \mathrm{pH}$ 8. $\alpha$ 7-nAChR-containing samples were resolved by SDSPAGE (6\% polyacrylamide) and subjected to immunoblotting as outlined above but for detection of APC and p-synapsin using specific antibodies. As a control to establish specificity of the $\alpha 7-\mathrm{nAChR}$ pull down, we coincubated the cellular extract and biotinylated $\alpha$-Btx mixture in the presence of an excess of nonbiotinylated $\alpha$-Btx $(10 \mu \mathrm{M})$ or nicotine (1 mM).

Pulse chase. Changes in $\alpha 7$-AChR levels at the cell surface were evaluated in hippocampal neurons exposed to Wnt-7a for different periods; biotinylated- $\alpha$-Btx $(1 \mu \mathrm{g} / \mathrm{ml})$ was added to cultures of live neurons for 45 min to visualize cell surface $\alpha 7-\mathrm{nAChRs}$ and at $4^{\circ} \mathrm{C}$ to inhibit nAChR endocytosis (Borroni et al., 2007). Neurons were subsequently lysed in RIPA buffer, and lysates were incubated with streptavidin-Sepharose and washed as described above except that first supernatants were saved to analyze intracellular $\alpha 7$-nAChRs. Surface $\alpha 7$-nAChRs and first supernatants were resolved using SDS-PAGE ( $8 \%$ polyacrylamide) and analyzed by Western blots with rabbit anti-nAChR $\alpha 7$ subunit antibody (Santa Cruz Biotechnology).

Determination of total levels of $\alpha 7-n A C h R s$ and DVL phosphorylation. Cells were lysed in buffer A. Protein concentrations were determined using the BCA Protein Assay Kit (Pierce Biotechnology, Rockford, IL). Forty microgram samples of cell lysates were resolved by SDS-PAGE ( $8 \%$ polyacrylamide) followed by immunoblotting on PVDF membranes using rabbit anti-nAChR $\alpha 7$ subunit or mouse anti-dishevelled-3 (DVL-3) antibody (Santa Cruz Biotechnology). 
Immunohistochemistry. Hippocampal neurons were subjected to different treatments while on coverslips inside 24 -well plates at a plating density of 30,000 cells/coverslip, fixed with $4 \%$ paraformaldehyde in PBS for $45 \mathrm{~min}$, permeabilized with $0.1 \%$ Triton X-100, and stained with the following antibodies: rabbit polyclonal anti-nAChR $\alpha 7$ subunit, rabbit polyclonal anti-APC, goat polyclonal anti-synaptic vesicle protein 2 (SV2), goat polyclonal anti-p-synapsin, and goat polyclonal antisynaptotagmin I a/b as presynaptic markers, goat polyclonal antiPSD-95 as a postsynaptic marker, monoclonal anti-AT8 as an axonal marker, and monoclonal anti-microtubule-associated protein 2 $(\mathrm{MAP} 2 \mathrm{a} / \mathrm{b})$ as a dendrite marker followed by Alexa ${ }^{488}$-, Alexa $^{543}$-, or Alexa ${ }^{633}$-conjugated secondary antibodies. Phalloidin coupled to Alexa ${ }^{633}$ was used as neurite marker. In some experiments, $\alpha 7$-nAChRs were labeled with rhodamine (Rhod)- $\alpha$-Btx in permeabilized cells. Double-labeling experiments with anti-nAChR $\alpha 7$ subunit antibody (Santa Cruz Biotechnology) and Rhod- $\alpha$-Btx- gave coincident labeling patterns, supporting the correlation between the $\alpha 7$ subunit-like antigens and $\alpha$-Btx-binding $\alpha 7$-nAChRs. Digital images of neurons on coverslips were captured with a Zeiss (Oberkochen, Germany) confocal microscope using a $63 \times / 1.4$ numerical aperture oil-immersion objective. To determine the number of clusters within 10 or $100 \mu \mathrm{m}$ of neurite length and the major axis length of each cluster $(\mu \mathrm{m})$, images were analyzed using the LSM 5 Image Browser. Clusters were defined as puncta of $0.8-3 \mu \mathrm{m}$ in major axis length. For quantification of cluster size, length values were compared with those of control treatments. To identify somatic $\alpha 7-\mathrm{nAChR}$ and determine fluorescence staining intensity and numbers of $\alpha 7$-nAChR-containing clusters, 30 soma expressing GFP were examined for each treatment using Image J.

Colocalization image analysis. Colocalization analysis was performed on randomly selected images $(n=15)$ using NIH Image J software with the colocalization analysis plug-in. Mander's coefficients $(M)$ represent the fraction of pixels in which the two signals overlap or are colocalized (Manders et al., 1993). Mander's coefficients range from 0 for no colocalization to 1 for complete colocalization and are not influenced by differences in absolute signal intensities in each channel, because pixel intensity in a particular channel is normalized to total pixel intensity across the image for that label (pixels with a value of zero intensity in both channels are considered to be background and are ignored in the computations). The intensity correlation quotient (ICQ) represents the synchrony around which two signals vary and is based on nonparametric sign-test analysis of the product of the differences from the mean (PDM). In an image in which the intensities of staining of two targets vary together, the PDM will be positive. However, if the pixel intensities vary asynchronously, then most of the PDM values will be negative. ICQ values are calculated first by determining the ratio between the number of positive PDM values and the total number of pixel values. From this ratio, 0.5 is subtracted to yield ICQ values distributed between -0.5 and +0.5 where random staining gives an ICQ of $\sim 0$, segregated or asynchronous staining gives $0>$ ICQ $\geq-0.5$, and dependent or synchronous staining yields $0<\mathrm{ICQ} \leq+0.5$ ( $\mathrm{Li}$ et al., 2004).

Statistical analysis. Values were expressed as mean \pm SEM. Statistical significance of differences was assessed with the Student's $t$ test for unpaired samples from different, independent experiments. Differences were assessed for significance at $p<0.01$ based on nonpaired Student's $t$ test. Statistical assessment used in colocalization image analyses was performed according to the data distribution; normally distributed data were analyzed using two-tailed $t$ tests, and non-normally distributed data were analyzed using the Mann-Whitney $U$ test $(p<0.05$ was considered significant).

\section{Results}

\section{Human $\alpha 7-\mathrm{nAChRs}$ interact with APC in SH-EP1-h $\alpha 7$ cells}

Initial studies to test for possible interactions between $\alpha 7$ nAChRs and proteins involved in the Wnt signaling system used SH-EP1 cells stably expressing the human nAChR $\alpha 7$ subunit (SH-EP1-h $\alpha 7$ cells) (Zhao et al., 2003). Western analyses demonstrated the expression of several proteins involved in the Wnt pathway. SH-EP-1-h $\alpha 7$ cells express Fzd (Frizzled) receptors, which are the first targets of the Wnt canonical ligands, and different DVL isoforms, which are proteins that play an essential role in the dissociation of $\beta$-catenin from the destruction complex (Aberle et al., 1997). $\beta$-Catenin, the main effector of the Wnt pathway, and axin, APC, and GSK-3 $\beta$, which are different components of the $\beta$-catenin destruction complex (Fig. $1 A a$ ), were also found to be expressed in SH-EP-1-h $\alpha 7$ cells (data not shown).

To study the possible interaction of $\alpha 7$-nAChRs with components of the Wnt pathway, we assessed levels of coimmunoprecipitation of $\alpha 7$-nAChRs with proteins that play important roles in the regulation of the Wnt pathway. $\alpha 7$-nAChRs were found to interact with APC but not with $\beta$-catenin, DVL-3, or GSK-3 $\beta$ under control conditions (data not shown). To evaluate the ability and specificity of anti-nAChR $\alpha 7$ subunit antibody to recognize $\alpha 7-\mathrm{nAChR}$ expressed in SH-EP1-h $\alpha 7$ cells and not other proteins, we compared immunoblots performed using extracts from nAChR-null SH-EP1 cells and transfected SH-EP1-h $\alpha 7$ cells and found labeling of a specific protein band at the appropriate molecular mass only in SH-EP1-h $\alpha 7$ cells (data not shown).

These results validated some of the reagents to be used, indicated that human $\alpha 7-\mathrm{nAChRs}$ are able to interact with APC in the Wnt signaling pathway in SH-EP1-h $\alpha 7$ cells, and stimulated us to explore these relationships in neurons.

\section{$\alpha 7$-nAChRs interact with APC in hippocampal neurons}

Activation of canonical Wnt signaling leads to $\beta$-catenin stabilization and translocation into the nucleus to activate target genes (Nusse and Varmus, 1992), but the role of APC outside the destruction complex is not known. In rat hippocampal neurons, APC has been shown to be localized in the cytoplasm, in which it normally forms complexes with several proteins that lead to $\beta$-catenin degradation (Aberle et al., 1997; Brakeman et al., 1999). Hippocampal neurons also express other members of the Wnt signaling pathway and $\alpha 7$-nAChRs (Fabian-Fine et al., 2001; Farías et al., 2004).

A series of studies was done to confirm the presence of functional Wnt signaling in hippocampal neurons and to verify the presence of $W n t$ ligand in conditioned media used to bathe HEK293 cells transfected to express Wnt-7a and its absence in control media used to bathe HEK-293 cells transfected with an empty pcDNA vector. Wnt ligands able to activate the Wnt signaling pathway induce a phosphorylation-dependent mobility shift of DVL (Cong et al., 2004; Gonzalez-Sancho et al., 2004; Schulte et al., 2005). When hippocampal neurons were incubated with conditioned medium containing Wnt-7a ligand for $1 \mathrm{~h}$, a shift was observed from a fast-migrating form evident in control samples ("pcDNA") to a slower-migrating phosphorylated form of DVL-3 (Fig. 1 $A b$ ). As a consequence of DVL phosphorylation after $W n t$ pathway activation, $\beta$-catenin accumulates (Aberle et al., 1997). In hippocampal neurons, we also observed a twofold increase in $\beta$-catenin levels after exposure to Wnt-7a (Fig. $1 \mathrm{Ad}$ ).

To further assess the integrity of the Wnt signaling pathway in hippocampal neurons and functional activity of Wnt-7a in conditioned medium, we determined the extent of interaction between APC as the immunoprecipitation target and $\beta$-catenin as assessed by Western analysis. In hippocampal neurons treated with $W n t-7 a$ for $1 \mathrm{~h}$, there was dissociation of $\beta$-catenin from APC relative to levels of association under control conditions (Fig. 1Ac).

To evaluate whether endogenous $\alpha 7$-nAChRs interact with endogenous APC in rat hippocampal neurons, we performed an 


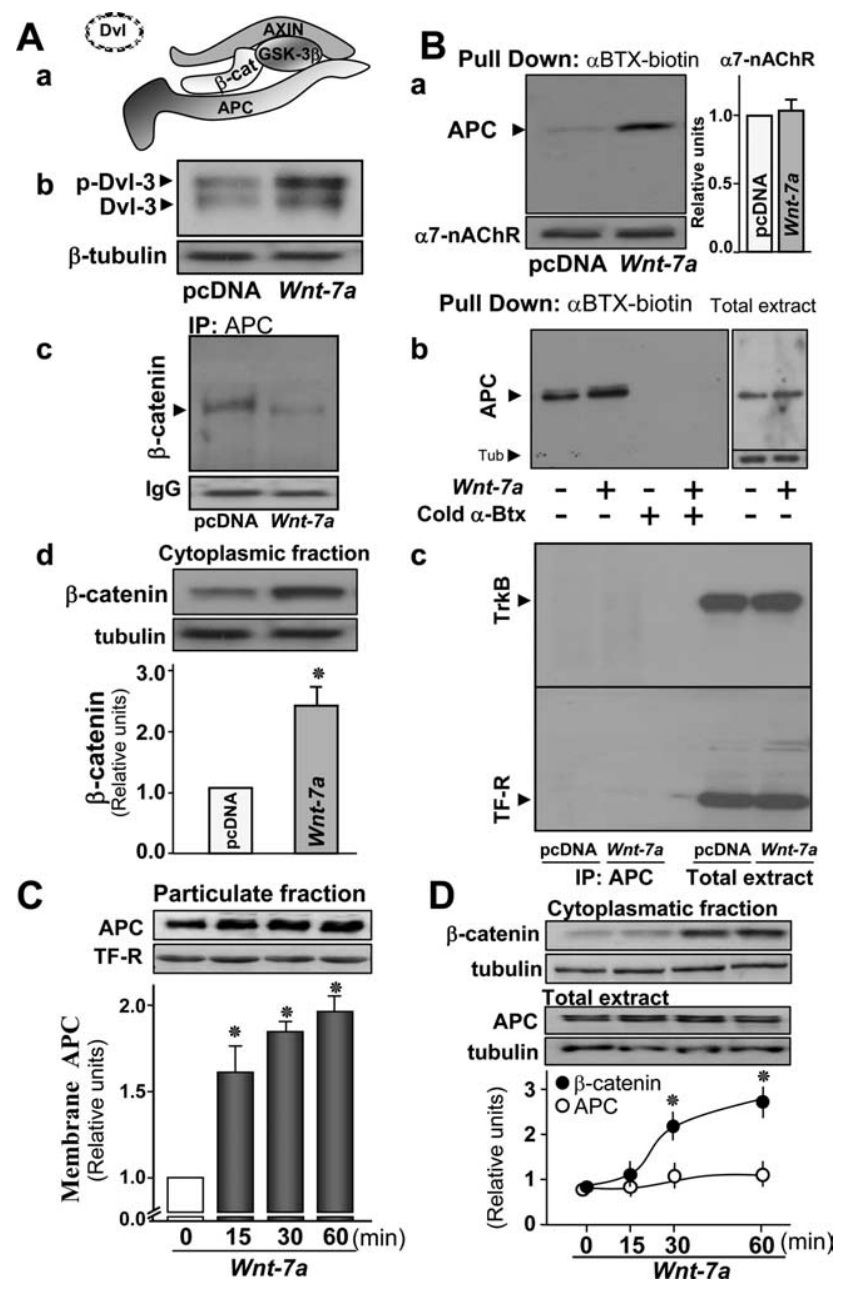

Figure 1. APC dissociates from the $\beta$-catenin cytoplasmic complex and associates with $\alpha 7$-nAChRs and membrane compartments in hippocampal neurons in the presence of Wnt-7a. $\boldsymbol{A} \boldsymbol{a}$, Schematic representation of the $\beta$-catenin destruction complex. $\boldsymbol{A} \boldsymbol{b}$, Western blot analysis after Wnt-7a treatment of hippocampal neurons for $1 \mathrm{~h}$ reveals increased phosphorylation of DVL-3 normalized for sample loading with tubulin (representative of $n=3$; $p c D N A$ represents the control condition using conditioned medium without secreted Wnt-7afrom transfected cells). $A c$, Ad, Immunoprecipitation (IP) of APC and Western detection of $\beta$-catenin indicates that the $\beta$-cate$\mathrm{nin} / \mathrm{APC}$ complex dissociates after Wnt-7a treatment under conditions in which total $\beta$-catenin is not altered ( $A c$; representative of $n=3$ ), whereas Wnt-7a induces $\beta$-catenin stabilization in the cytoplasmic fraction marked by the presence of and normalized for sample loading with tubulin (Ad; $n=$ 4; bar graph shows quantitation). $\boldsymbol{B} \boldsymbol{a}, \boldsymbol{B} \boldsymbol{b}, \mathrm{APC}$ interaction as determined by Western analysis with $\alpha 7$-nAChRs and assessed after pull down of $\alpha 7$-nAChRs using biotinylated- $\alpha$-Btx/streptavidinagarose is increased after exposure to Wnt-7a relative to pcDNA controls and normalized for total $\alpha 7$-nAChRs recovered, which is unchanged by ligand exposure ( $B \boldsymbol{a} ; n=4$; bar graph shows $\alpha 7$ $n A C h R$ quantitation) and is prevented in the presence of excess, fluid-phase Btx under conditions in which total APC levels are not altered $(\boldsymbol{B} \boldsymbol{b} ; n=3) . \boldsymbol{B} \boldsymbol{C}$, Immunoprecipitation of APC and detection by Western blot of associated TrkB receptor or TF-R reveals no nonspecific receptor interaction with APC under conditions in which total receptor numbers are high and unchanged by Wnt-7a exposure. $\boldsymbol{C}$, Subcellular fractionation and Western blot of APC normalized to transferrin receptor levels indicates increases in APC localization to the particulate fraction in a time-dependent form in the presence of Wnt-7a $(n=4)$. D, Western blot analysis of $\beta$-catenin levels in the cytoplasmic fraction and of APC in total extracts indicates that $\beta$-catenin levels increase and become stabilized at $30 \mathrm{~min}$ and that total APC levels are not affected over the same time course of Wnt-7a treatment ( $n=4$; normalized to $\beta$-tubulin levels). Data are the mean \pm SEM of three to six independent experiments, expressed as fold increase over control cells. In all figures, ${ }^{*} p<0.01$ by nonpaired Student's $t$ test.

immunoprecipitation of the $\alpha 7$-nAChR and detection of APC by Western analysis. We observed an interaction between $\alpha 7$ nAChRs and APC (data not shown). However, because of concerns that anti-nAChR $\alpha 7$ subunit antibodies might engage in nonspecific interactions with other proteins in mouse brain extracts (Herber et al., 2004), we also assessed $\alpha 7$-nAChR/APC interactions using biotinylated- $\alpha$-Btx to pull down intact toxinbinding $\alpha 7$-nAChRs from hippocampal neurons and assess their interaction with APC. Under basal conditions (data not shown) or in the presence of control medium (pcDNA) (Fig. $1 B a$, first lane and first column), we detected APC in $\alpha 7$-nAChR complexes, as was indicated in the coimmunoprecipitation assays.

To determine whether activation of Wnt signaling promotes stronger interaction between $\alpha 7$-nAChRs and APC, hippocampal neurons were incubated for $1 \mathrm{~h}$ in the presence of $W n t-7 a$ ligand. This treatment specifically (relative to controls) (Fig. $1 \mathrm{Ba}$, first lane and first column) induced stronger association of APC with $\alpha 7$-nAChRs (Fig. $1 B a$, second lane and second column) under conditions in which total APC (Fig. $1 B b$, right, $D$ ) and total $\alpha 7$-nAChR level (Fig. $1 \mathrm{Ba}$ ) remained unchanged. If $\alpha 7$-nAChR interaction with biotinylated $\alpha$-Btx was inhibited in the presence of excess unlabeled toxin (Fig. $1 \mathrm{Bb}$ ) or nicotine (data not shown), APC was not isolated as assessed by immunoblots in the streptavidin-Sepharose samples that lacked immobilized $\alpha 7$ $\mathrm{nAChR}$. To further demonstrate specificity of interactions between $\alpha 7$-nAChRs and APC, we immunoprecipitated APC and used Western analysis to assess APC interactions with receptors for transferrin or Trk-B, both of which are present in hippocampal neuron plasma membranes. No interactions between APC and Trk-B or transferrin receptors were detected in either Wnt$7 a$-treated or control neurons, even under conditions in which blots were overexposed with regard to receptor levels in total extracts to enhance the possibility of visualizing these interactions (Fig. $1 B c$ ).

These results show that the canonical Wnt-7a ligand induces the dissociation of APC from the $\beta$-catenin cytoplasmic complex and the association of APC with $\alpha 7$-nAChRs in hippocampal neurons.

\section{APC is associated with membranes and forms clusters in hippocampal neurites.}

Having demonstrated that APC interacts with $\alpha 7$-nAChRs, the possible association of APC with membranes was studied in rat hippocampal neurons as a function of time of exposure to Wnt$7 a$. Particulate fractions were obtained by subcellular fractionation, and Wnt-7a was found to induce the association of APC with membrane-enriched compartments (as assessed by the presence of transferrin receptor) in a time-dependent manner (Fig. 1C). Fifteen minutes of incubation with Wnt-7a induced a 1.6fold increase in membrane-bound APC, reaching plateau values of twofold over control after $60 \mathrm{~min}$ of Wnt ligand exposure (Fig. $1 C)$. Under the same conditions, the total levels of APC did not change (Fig. 1D). The stabilization of $\beta$-catenin in cytoplasmic fractions marked by the presence of tubulin was observed after 30 min of Wnt-7a treatment and was maintained at $60 \mathrm{~min}$ of Wnt ligand exposure (Fig. 1D). The observation that APC is dissociated from $\beta$-catenin and that the APC association with membranes precedes $\beta$-catenin stabilization could indicate that interactions between APC and $\alpha 7$-nAChR do not require association of APC with $\beta$-catenin.

We next sought to determine whether Wnt-7a induces changes in the localization of APC in hippocampal neurons as evaluated by immunofluorescence. In control cells, APC was found mainly in neuronal soma, with a weak localization in neurites (Fig. $2 \mathrm{Aa}$ ). Remarkably, Wnt-7a treatment induced the relocalization of APC to neurites, in which APC appeared in the form of clusters (Fig. 2Ab,Ac). As a test of specificity of these 

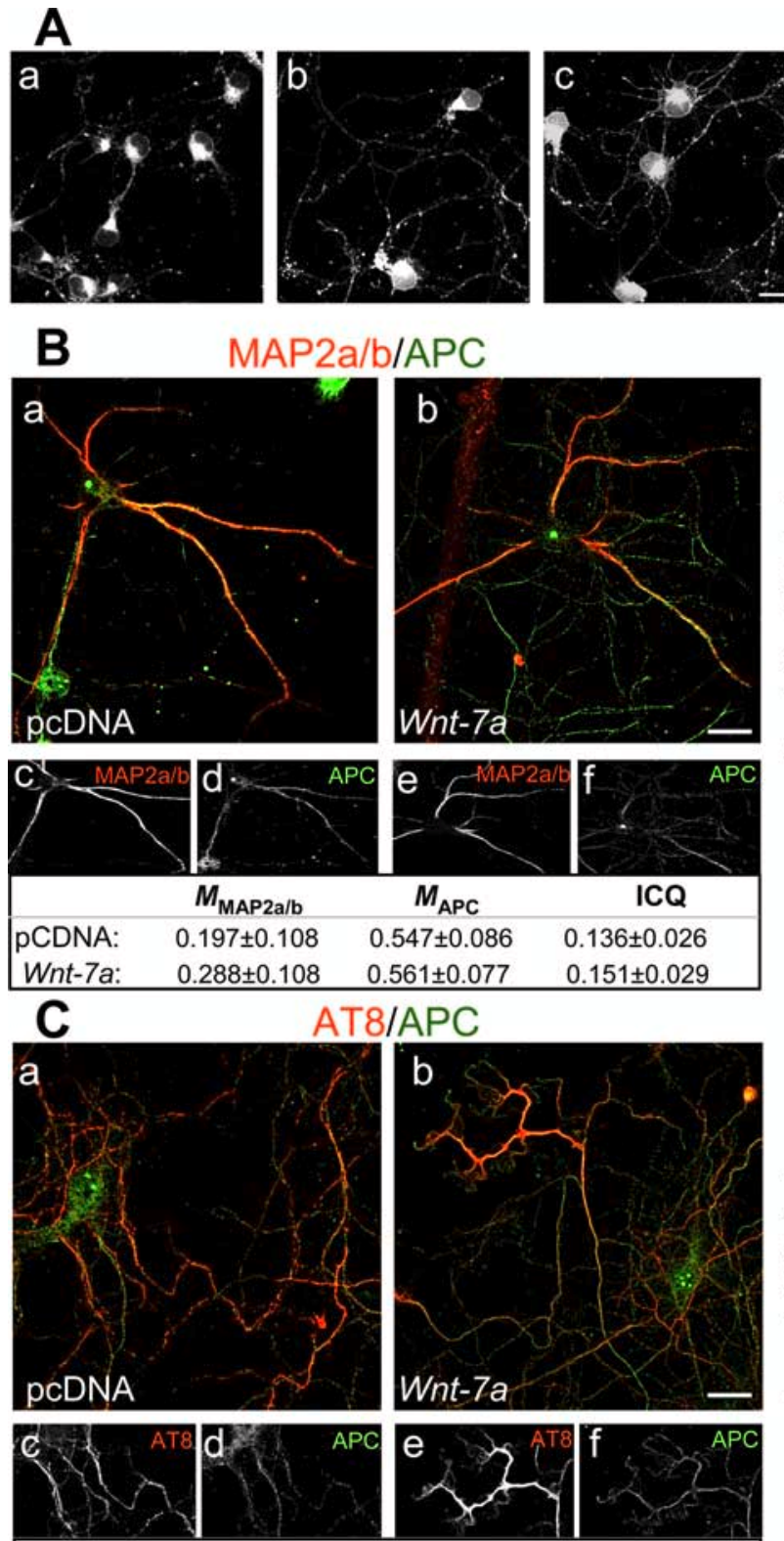

$M_{\text {AT8 }}$

$M_{\text {APC }}$

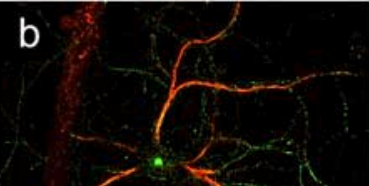

pCDNA:

$0.345 \pm 0.113$

$0.426 \pm 0.113$

$0.497 \pm 0.072^{*}$

$0.526 \pm 0.075$ *
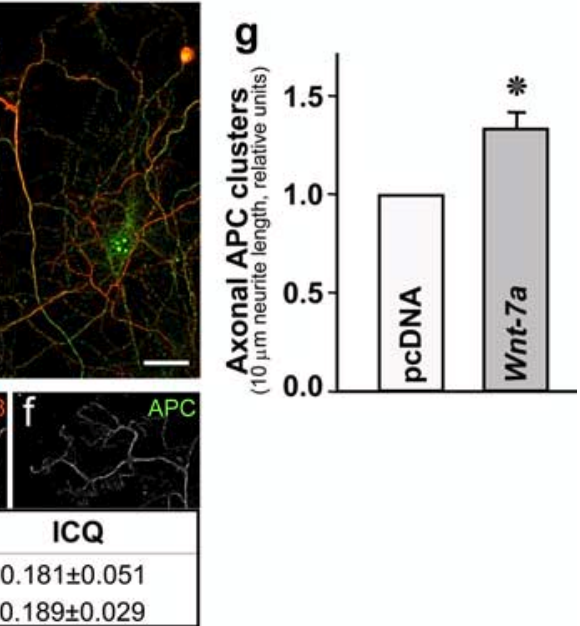

Figure 2. Wnt-7a induces clustering of APC in neurites. $A$, Immunofluorescence for APC indicates that $A P C$ clusters as puncta in neurites and that these APC aggregates increase after Wnt-7a treatment for $0 \mathrm{~min}(\boldsymbol{A a}), 15 \mathrm{~min}(\boldsymbol{A b})$, and $60 \mathrm{~min}(\boldsymbol{A c})$. Scale bar, $10 \mu \mathrm{m}$. Ad, Quantification of APC puncta per $100 \mu \mathrm{m}$ of neurites demonstrates time dependence for increased APC Wnt-7ainduced puncta and sensitivity of puncta formation to cotreatment with sFRP. Data are the mean \pm SEM of six independent experiments performed in duplicate. $B$, Double immunofluorescence for $A P C$ and MAP2a/b shows that, under control conditions (pcDNA), APC is localized in the soma and dendrites $(\boldsymbol{B a}, \boldsymbol{B C}, \boldsymbol{B} \boldsymbol{d})$, whereas Wnt-7a treatment induces neuritic localization of APC but not to MAP2a/b-positive dendrites $(\boldsymbol{B} \boldsymbol{b}, \boldsymbol{B} \boldsymbol{e}, \boldsymbol{B} \boldsymbol{f})$. Table, Colocalization analysis $(M)$ and ICQ values. $\boldsymbol{B} \boldsymbol{g}$, The number of dendritic APC clusters is not affected by Wnt-7a treatment relative to control conditions. Scale bar, $10 \mu \mathrm{m}$. C, Double immunofluorescence for APC and p-Tau recognized by AT8 antibody shows that Wnt-7a induces APC relocalization to p-Tau-positive axons $(\boldsymbol{C b}, \boldsymbol{C e}, \boldsymbol{C} \boldsymbol{f})$ relative to control conditions ( $\mathrm{pCDNA} ; \boldsymbol{C} \boldsymbol{a}, \boldsymbol{C}, \boldsymbol{C d} ; 3$ independent experiments performed in triplicate). Table, colocalization analysis $(M)$ and ICQ values. $\mathrm{C}$, Wnt-7a treatment increases the number of APC clusters in axons relative to control conditions. Scale bar, $10 \mu \mathrm{m}$.

effects, a strategy was used that involved coincubation of Wnt-7a ligand with sFRP. sFRP recaptures the Wnt ligands, thereby preventing their interaction with cellular membrane-bound Frizzled receptors. Treatment of rat hippocampal neurons with both Wnt-7a and sFRP-conditioned media prevented APC clustering in neurites (images not shown), indicating the specificity of Wnt ligand action. Quantification of the numbers of APC clusters per $100 \mu \mathrm{m}$ of neurite length showed that Wnt-7a induced a time-dependent appearance of APC clusters on neurites that was prevented in the presence of sFRP (Fig. 2Ad).

We used MAP2a/b as a marker to evaluate whether Wnt-7a-mediated translocation and clustering of APC in neurites involves dendrites. Under control conditions, APC is localized in the soma and in some neurites that correspond to MAP2a/b-labeled dendrites (Fig. $2 B a, B$ $c, B d)$. Colocalization analysis indicates that a fraction $(\sim 20 \%)$ of MAP $2 \mathrm{a} / \mathrm{b}$ colocalized with APC and that a fraction $(\sim 55 \%)$ of APC colocalized with MAP2a/b (Fig. $2 B$, table). However, there was no significant increase in APCMAP2a/b colocalization in hippocampal neurons exposed to Wnt-7a (Fig. $2 B b, B e, B f$, table), and there was no significant difference in the synchrony of signal variation (no change in ICQ values, which nevertheless demonstrate overall synchrony in colocalization of staining). Moreover, Wnt-7a treatment for $1 \mathrm{~h}$ induced clustering of APC in neurites (Fig. $2 A$ ), but we did not find an increase in the number of clusters contained in MAP2a/ b-positive neurites (Fig. $2 \mathrm{Bg}$ ).

To determine whether the APC clusters induced by Wnt-7a were axonal, we used phosphorylated Tau protein recognized by the AT8 antibody as a marker. Under control conditions, a fraction of APC $(\sim 43 \%)$ colocalized with AT8-labeled antigen, and a fraction $(\sim 35 \%)$ of phospho-Tau colocalized with APC (Fig. $2 C a, C c, C d$, table). $W n t-7 a$ treatment significantly increased the colocalization of APC and phosphoTau (Fig. 2Cb,Ce,Cf, table). Moreover, Wnt-7a increased APC clusters in AT-8positive neurites relative to control conditions (Fig. 2Cg). These results suggest that Wnt-7a induces a functionally relevant relocation of APC to axons in mature hippocampal neurons.

\section{Wnt-7a induces APC clustering in}

presynaptic but not in postsynaptic sites in hippocampal neurons

The presence of APC at synapses and more specifically in postsynaptic regions has been demonstrated at the neuromuscular junction and in ciliary ganglion neurons (Wang et al., 2003; Temburni et al., 2004). To determine whether APC is present in postsynaptic regions of hippocampal neurons, we evaluated whether it is associated with PSD-95, a scaffold protein that, for example, maintains the glutamate receptors anchored to the plasma membrane (Sheng, 2001). Control 
hippocampal neurons exhibit a typical, clustered distribution of PSD-95 in dendrites (Fig. $3 A a, B a$ ). In contrast, APC is only expressed in the soma and in some neurites but not in a clustered pattern (Fig. $3 A b, B b)$. When hippocampal neurons were exposed to $W n t-7 a$ for $1 \mathrm{~h}$, a clear redistribution of APC to clusters in neurites was observed (Fig. $3 A f, A h, B e, B f$ ). Moreover, we found that the pixel intensity for PSD-95 colocalized with APC increased significantly with Wnt-7a treatment but only increased marginally in the colocalization of APC with PSD-95 (Fig. $3 B$, table) (synchrony of signal covariation is indicated by positive ICQ values) despite the fact that the number of APC clusters, but not of PSD-95 clusters or APC/PSD-95 coclusters, increased with $W n t-7 a$ treatment (Fig. 3Bj). The effect of Wnt-7a was specific, because neurite APC cluster formation was prevented by coincubation with sFRP (Fig. 3Bh,Bi). Interestingly, treatment with sFRP alone also reduced the detection of APC in neurites (data not shown), suggesting a role for endogenous Wnt ligands in hippocampal neurons. This is consistent with the observation that hippocampus and hippocampal neurons cultures express Wnt-7a ligand (W. Cerpa, I. E. Alfaro, G. G. Farias, R. A. Fuentealba, M. J. Metcalfe, J. A. Godoy, C. Bonansco, and N. C. Inestrosa, unpublished observations).

Many of the APC clusters induced by Wnt-7a exposure were localized opposite the PSD-95 clusters, suggesting that APC relocalizes in synapses but not preferentially to postsynaptic excitatory terminals (Fig. $3 A h$, inset). To determine whether Wnt-7a induces presynaptic relocalization of APC, we used p-synapsin-1 and the synaptic vesicle proteins SV-2 and synaptotagmin-1 as markers. Each of these proteins exhibited a typical, clustered pattern in neuritic processes (Fig. $4 A a, A d, B-$ $a, B d, C a, C d)$. Under control conditions, APC could be observed in some neurites, in which it colocalized and coclustered with p-synapsin, SV-2, and synaptotagmin (Fig. $\quad 4 A b-A d, B b-B d, C b-C d)$. Wnt-7a treatment for $1 \mathrm{~h}$ induced higher levels of colocalization of APC with p-synapsin and synaptotagmin in neurites (Fig. $4 \mathrm{Ag}, \mathrm{Ah}$ $, C g, C h)$ but decreased the colocalization between APC and SV-2 (Fig. $4 \mathrm{Bg}, \mathrm{Bh}$ ). APC and presynaptic marker staining intensities varied in a dependent manner under control or $W n t-7 a$ treatment conditions (Fig. 4 , tables, positive ICQ values), although the lack of effect of Wnt-7a treatment on absolute ICQ values [except the small decrease in APC/SV-2 staining synchrony (Fig. 4, tables)] suggests that the redistribution of APC induced by Wnt-7a is not caused by a redistribution of the presynaptic markers. Quantification showed increases of $70-80 \%$ in APC clusters in neurons treated with $W n t-7 a$, an almost 70\% increase in SV-2 and synaptotagmin clusters, but no change in p-synapsin clusters (Fig. $4 \mathrm{Ai}, \mathrm{Bi}, \mathrm{Ci}$ ). Interestingly, Wnt-7a exposure increased the number of APC clusters colocalized with p-synapsin, SV-2, and synaptotagmin in hippocampal neurons (Fig. $4 \mathrm{Ai}, \mathrm{Bi}, \mathrm{Ci}$ ). Because there was a decrease in the absolute colocalization of APC and SV-2 staining intensity but an increase in APC/SV-2 coclustering, we suggest that there is diffuse colocalization of APC and SV-2 under control conditions but that Wnt-7a treatment induces an increase in the size of clusters containing these proteins. The results indicate that $W n t-7 a$ induces presynaptic relocalization of APC and suggest that Wnt-7a, through APC, may play 

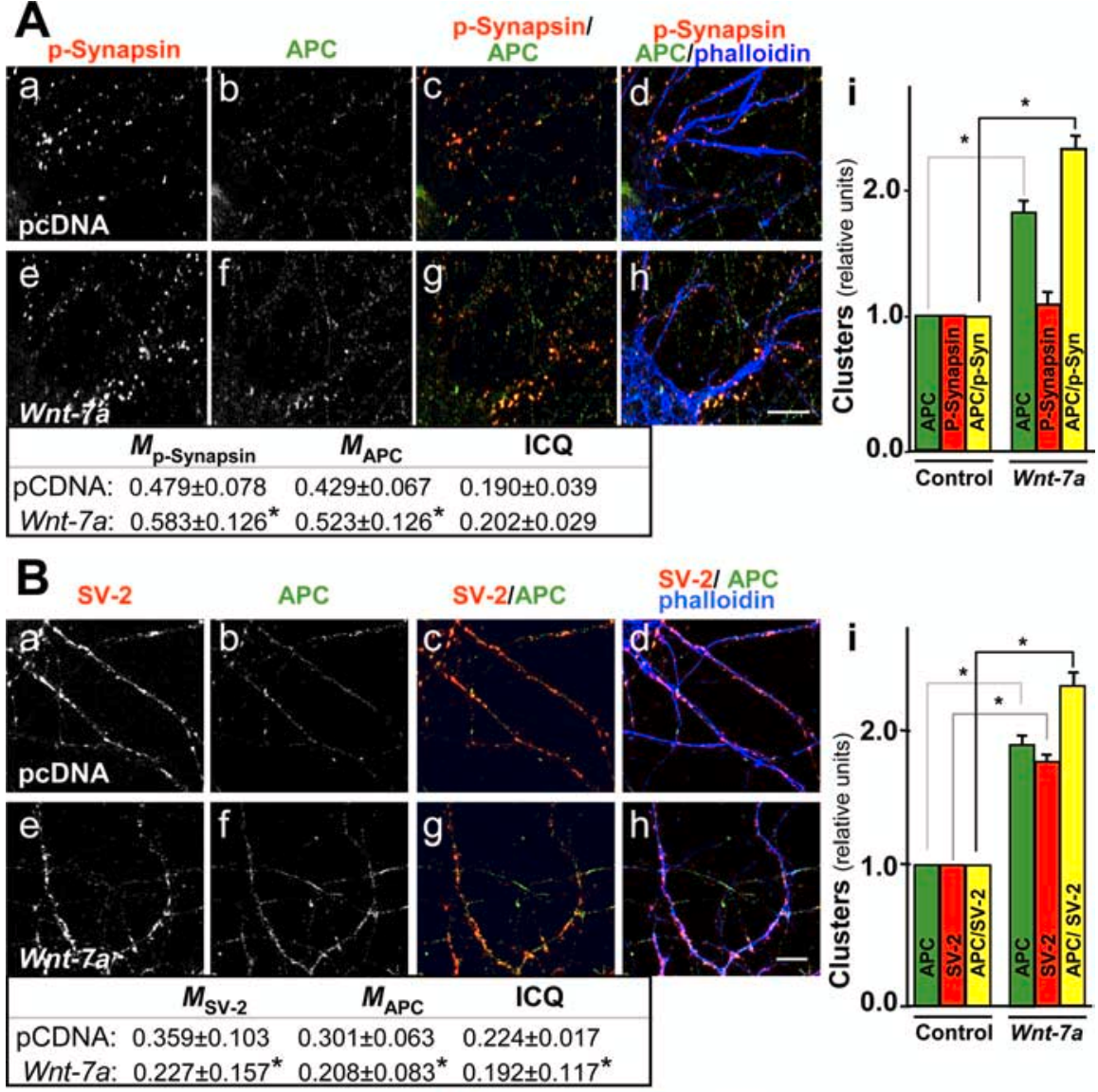

SV-2I APC
phalloidin
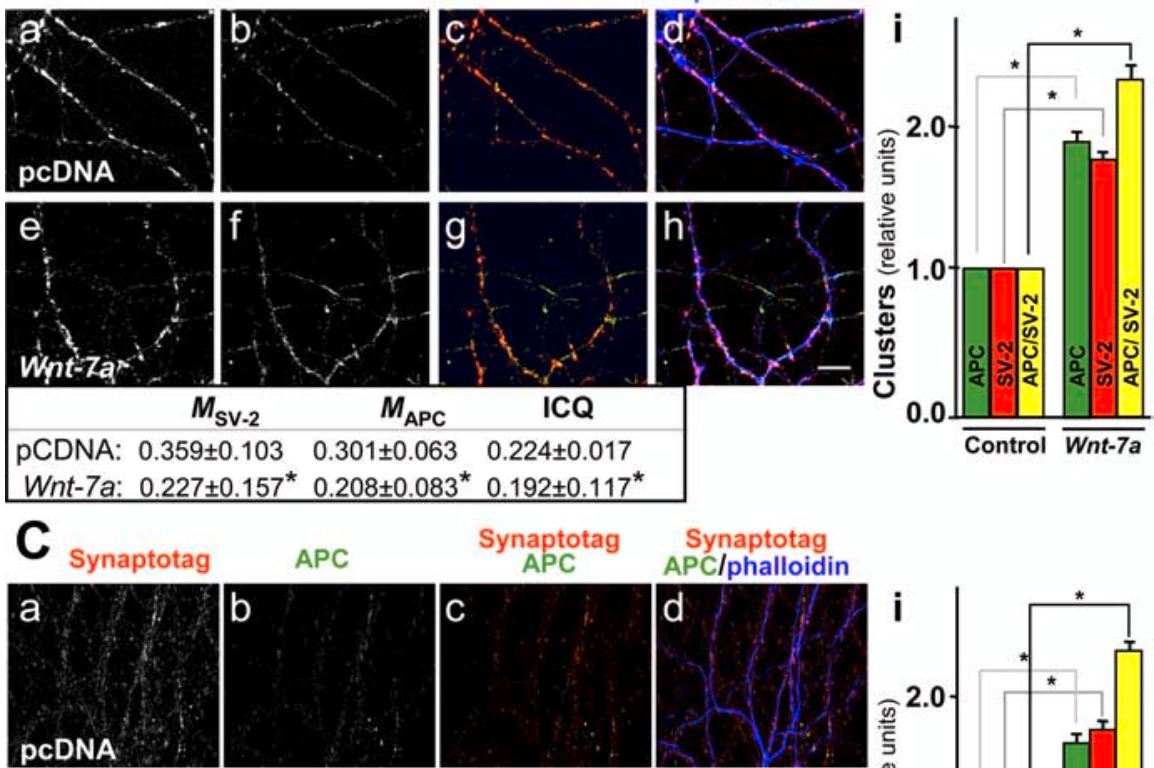

Synaptotag
APClphalloidin
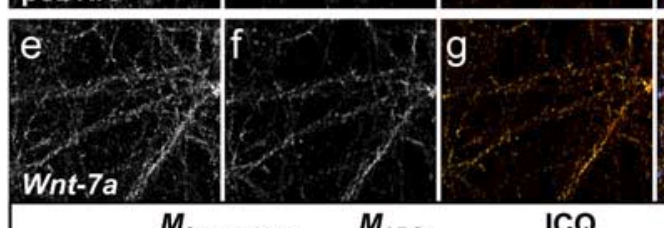

ICQ

pCDNA: $0.374 \pm 0.042 \quad 0.626 \pm 0.029 \quad 0.134 \pm 0.006$

Wnt-7a: $0.509 \pm 0.081^{*} 0.744 \pm 0.047^{*} 0.144 \pm 0.017$

Figure 4. Wnt-7a induces clustering of APC in presynaptic sites in hippocampal neurons. $A$, Immunofluorescence labeling of hippocampal neurons for p-synapsin $(\boldsymbol{A a}, \boldsymbol{A e})$ or $\mathrm{APC}(\boldsymbol{A} \boldsymbol{b}, \boldsymbol{A f})$ shows induction in coclustering in the presence of Wnt-7a $(\boldsymbol{A g}, \boldsymbol{A} \boldsymbol{h})$ relative to control (pcDNA) treatment $(\boldsymbol{A} \boldsymbol{C}, \boldsymbol{A d})$ and as indicated in quantification $(\boldsymbol{A} \boldsymbol{A})$. $\boldsymbol{B}$, Double labeling of hippocampal neurons for SV-2 (Ba, Be) and $A P C(B \boldsymbol{B}, \boldsymbol{B} \boldsymbol{f})$ shows that Wnt-7a induces coclustering $(\boldsymbol{B g}, \boldsymbol{B h})$ relative to control conditions $(\boldsymbol{B C}, \boldsymbol{B d})$ and as quantified (Bi). C, Double labeling for synaptotagmin (Synaptotag; $\mathbf{C a}, \boldsymbol{C e})$ and $\operatorname{APC}(\boldsymbol{C b}, \boldsymbol{C} \boldsymbol{f})$ shows induction in coclustering in hippocampal neurons exposed to Wnt-7a $(\boldsymbol{C g}, \boldsymbol{C h})$ relative to controls $(\boldsymbol{C} \boldsymbol{c}, \mathbf{C d})$ and as indicated by quantification (Ci). Scale bars, $10 \mu \mathrm{m}$. Tables, Colocalization analysis $(M)$ and ICQ values.

some role in restructuring the presynaptic region in mature hippocampal neurons.

Wnt-7a induces presynaptic localization of $\alpha 7$-nAChRs.

Recent evidence from our laboratory indicates that Wnt-7a induces synaptic vesicle exocytosis from presynaptic regions of hippocampal neurons (Cerpa, Alfaro, Farias, Fuentealba, Metcalfe, Godoy, Bonansco, and Inestrosa, unpublished observations). Furthermore, $\alpha 7$-nAChRs expressed presynaptically on hip- pocampal neurons modulate transmitter release from GABAergic and glutamatergic terminals (Radcliffe and Dani, 1998; Alkondon and Albuquerque, 2001; Kawai et al., 2002). We evaluated the possible role of Wnt signaling in modulation of the synaptic localization of $\alpha 7$-nAChRs and their interaction with presynaptic proteins. Immunoprecipitation of $\alpha 7$-nAChRs followed by immunodetection of VAMP-1/2, a component of synaptic vesicles that forms the SNARE (soluble $N$-ethylmaleimide-sensitive factor attachment protein receptor) fusion complex enabling vesicle exocytosis (Sytnyk et al., 2004), showed that $\alpha 7$-nAChRs interact weakly with VAMP-1/2 in control hippocampal neurons (Fig. 5A). However, treatment for $1 \mathrm{~h}$ with Wnt-7a induced a strong association of $\alpha 7$-nAChRs with VAMP-1/2 (Fig. $5 A)$. Under similar conditions, total levels of VAMP-1/2 were not changed. Moreover, pull-down assays involving biotinylated- $\alpha$-Btx-mediated capture of $\alpha 7$-nAChR showed increased association of receptor with p-synapsin under conditions in which total levels of p-synapsin remained the same (Fig. 5A).

Evaluation of the interaction between $\alpha 7$-nAChRs and SV-2 under control conditions demonstrated colocalization of these proteins (Fig. $5 B a-B c, C a-C c$ ). Wnt-7a exposure induced a decrease in the fraction of $\alpha 7$-nAChRs that colocalized with SV-2 (Fig. $5 B d-B f, C d-C f$ ). Quantification showed a decrease in the number of $\alpha 7$-nAChRs clusters contained in the clusters of SV-2 in Wnt-7a-treated neurons under conditions in which the number of $\alpha 7$-nAChR and SV-2 clusters increased almost 70 and $40 \%$, respectively (Fig. $5 C g$ ). An increase in the cocluster size was apparent after Wnt-7a treatment (Fig. 5Cg). Similar results were observed for interactions between $\alpha 7$-nAChR and synaptotagmin (Fig. 6B).

PSD-95 was used as marker to evaluate possible interaction and coclustering with $\alpha 7$-nAChRs localized postsynaptically and to determine specificity of Wnt-7astimulated relocalization of $\alpha 7-\mathrm{nAChRs}$ presynaptically. Immunoprecipitation of $\alpha 7$-nAChRs and Western immunodetection of PSD-95 demonstrated interaction between these two proteins in hippocampal neurons under control conditions, but Wnt-7a exposure decreased interaction between $\alpha 7$-nAChRs and PSD-95 (Fig. 5D). Coclustering of $\alpha 7$ nAChRs with PSD-95 was observed under control conditions (Fig. $5 E a-E c$ ). However, Wnt-7a exposure did not affect pixellevel colocalization and instead decreased the ICQ value and the number of $\alpha 7$-nAChRs contained in PSD-95 clusters (Fig. 5Ed$E g$, table). These effects in the presence of Wnt-7a occurred under conditions in which $\alpha 7$-nAChR clusters increased in number and 
size but in which PSD-95 clusters were not affected (Fig. 5Eg). To assess whether $\alpha 7$ nAChRs relocalized to presynaptic domains were inserted into the plasma membrane in response to Wnt-7a exposure, hippocampal neurons were exposed to Wnt-7a ligand for different periods $(0-2$ h) at $37^{\circ} \mathrm{C}$, and the live neurons were then washed free of ligand. Samples were next exposed to biotinylated- $\alpha$-Btx for $45 \mathrm{~min}$ at $4^{\circ} \mathrm{C}$ to assess cell-surface levels of $\alpha 7$ nAChRs while also inhibiting endocytosis of the receptor. Wnt-7a exposure induced a time-dependent increase in number of $\alpha 7$-nAChRs inserted into the plasma membrane (i.e., isolated by streptavidinSepharose pull down of toxin-receptor complexes from lysed cells and visualized on immunoblots), with 1-2 h of treatment producing a $50 \%$ increase in surface receptors (Fig. 6A). There was a concomitant decrease in the amount of intracellular $\alpha 7$ nAChR (recovered as supernatants from pull-down samples and visualized on immunoblots) (Fig. 6A).

These results indicate that Wnt-7a signaling induces a redistribution of $\alpha 7$ nAChRs to presynaptic membrane regions.

\section{Wnt-7a signaling induces presynaptic} coclustering of APC and $\alpha 7-n A C h R s$ Because we observed that Wnt-7a induced $\alpha 7$-nAChR/APC interactions, APC localization to presynaptic sites, and $\alpha 7$ nAChR localization to presynaptic sites, we next used triple immunofluorescence to evaluate whether $W n t-7 a$ induces presynaptic colocalization of APC and $\alpha 7$ nAChRs. Exposure of hippocampal neurons to $W n t-7 a$ for $1 \mathrm{~h}$ induced the formation of clusters of immunoreactivity for synaptotagmin $1 \mathrm{a} / \mathrm{b}$ (Fig. $6 \mathrm{Ba}, \mathrm{Be}, \mathrm{C}$ ), a presynaptic protein that acts as a $\mathrm{Ca}^{2+}$ sensor and interacts with $\mathrm{Ca}^{2+}$ channels (Sytnyk et al., 2004). An increase in interactions between APC protein (Fig. $6 B b, B f$ ) and $\alpha 7$-nAChRs (Fig. $6 B c, B g$ ) in synaptotagmin clusters was evident after Wnt-7a treatment (Fig. 6Bh, arrows) but not in control samples (Fig. $6 \mathrm{Bd}$, arrows). Quantitative analysis revealed that Wnt-7a treatment clearly increased the size of presynaptic synaptotagmin $1 \mathrm{a} / \mathrm{b}$ clusters by $\sim 85 \%$ (Fig. 6Ca). Wnt-7a ligand treatment also induced a clear redistribution of APC, as observed previously, and an increase in cluster size to 2.6-fold of control levels (Fig. 6Ca). Moreover, $W n t-7 a$ increased the size of $\alpha 7$-nAChR clusters to $\sim 2.3$-fold of control size (Fig. 6Ca). Quantitative analysis confirmed impressions of a correlation between the sizes of APC and $\alpha 7-\mathrm{nAChR}$ clusters and an increase in the number and size of coclusters in the presence of $W n t-7 a$ in the presynaptic region (Fig. 6Cb) (data not shown).

C

$\alpha$ Btx-R

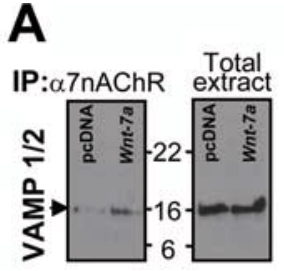

Pull Down: biotin- $\alpha \mathrm{Btx}$

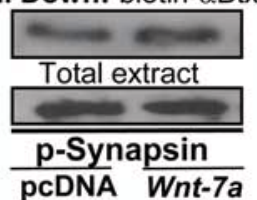

B
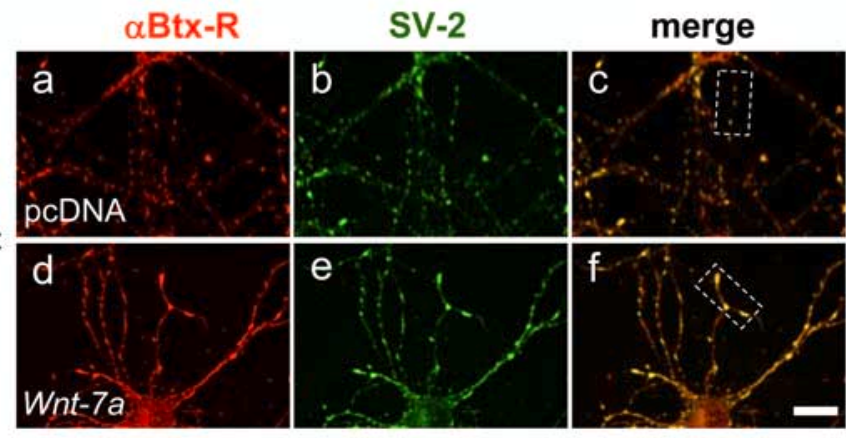

SV-2 $\alpha$ Btx-R/SV-2
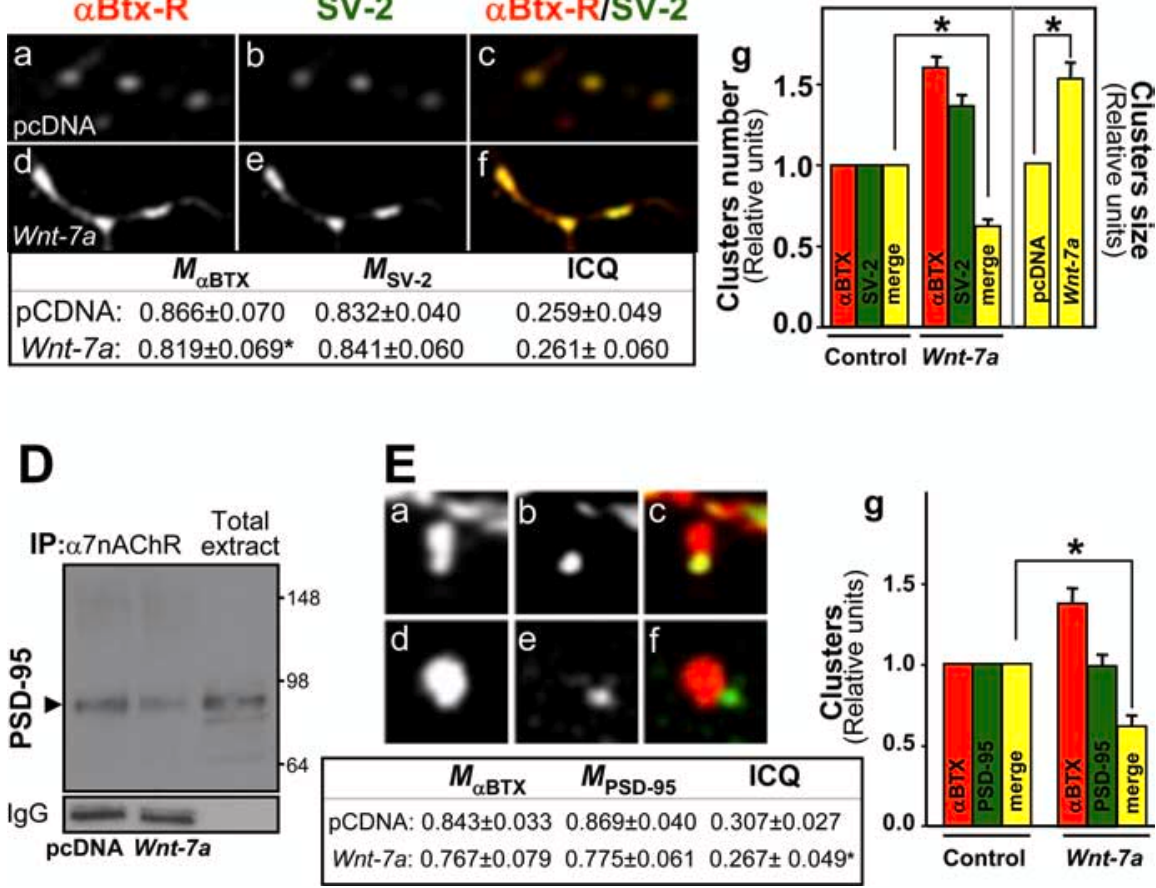

Figure 5. Wnt-7a increases presynaptic but not postsynaptic relocalization of $\alpha 7-n A C h R s$ in hippocampal neurons. $\boldsymbol{A}$, Immunoprecipitation (IP) of $\alpha 7-n A C h R s$ and Western blot for VAMP-1/2, a synaptic vesicle protein, shows that Wnt-7a exposure induces the association of $\alpha 7$-nAChRs with VAMP-1/2 under conditions in which the total levels of VAMP-1/2 are not affected ( $n=3$ ). Pull down of $\alpha 7-n A C h R s$ and Western blot of p-synapsin shows that Wnt-7a treatment induces the association of $\alpha 7$-nAChRs with p-synapsin, another presynaptic protein $(n=3)$. $\boldsymbol{B}$, Fluorescent rhodamine-labeled $\alpha$-Btx $(\alpha-B t x-R ; B \boldsymbol{B}, \boldsymbol{B d})$ or SV-2 immunofluorescence $(\boldsymbol{B b}, \boldsymbol{B e})$ staining in hippocampal neurons treated with control media (pcDNA; $\boldsymbol{B a}-\boldsymbol{B C})$ or Wnt-7a $(\boldsymbol{B d}-\mathbf{B f}$ ) indicates that Wnt-7a increases the interaction between $\alpha 7-n A C h R s$ and SV-2 (merged images; $\boldsymbol{B C}, \boldsymbol{B} \boldsymbol{f}$ ). Scale bar, 10 $\mu \mathrm{m}$. $\mathbf{C a}-\mathbf{C f}$, Magnified views of the boxed regions in Bcand $\boldsymbol{B f}$. $\mathbf{C g}$, Wnt-7a induced an increase in the size of $\alpha 7-n A C h R$ and SV-2 coclusters but not the number of clusters. D, Immunoprecipitation of $\alpha 7$-nAChRs and Western blot for PSD-95 shows $\alpha 7-n A C h R$ association with PSD-95 in control media (pCDNA)-treated samples and that Wnt-7a treatment decreases this association (representative of $n=3$ ). $\boldsymbol{E}$, Fluorescent rhodamine-labeled $\alpha$-Btx $(\boldsymbol{E} \boldsymbol{a}, \boldsymbol{E} \boldsymbol{d})$ or PSD-95 immunofluorescence $(\boldsymbol{E} \boldsymbol{b}, \boldsymbol{E} \boldsymbol{e})$ staining in hippocampal neurons treated with pcDNA (Ea-Ec) or Wnt-7a (Ed-Ef) indicates that Wnt-7a increases the size of $\alpha 7-n A C h R$ clusters but not coclustering with PSD-95. Eg, Quantification of $\alpha$-Btx staining ( $\alpha 7$-nAChRs) or PSD-95 clusters and of $\alpha 7$-nAChRs contained in PSD-95 clusters, demonstrating a decrease in coclustering after treatment with Wnt-7a ligand. C, E, Tables, Colocalization analysis $(M)$ and ICQ values.

Together, these experiments indicate that the canonical Wnt-7a ligand modulates the coclustering of APC and $\alpha 7$ $\mathrm{nAChR}$ in presynaptic sites and suggest a possible role of APC in the process.

Prolonged exposure to $W n t-7 a$ increases levels of $\alpha$ 7-nAChRs.

The conventional role of Wnt pathway activation involves modulation of gene expression through $\beta$-catenin/Tcf-LEF. The ef- 

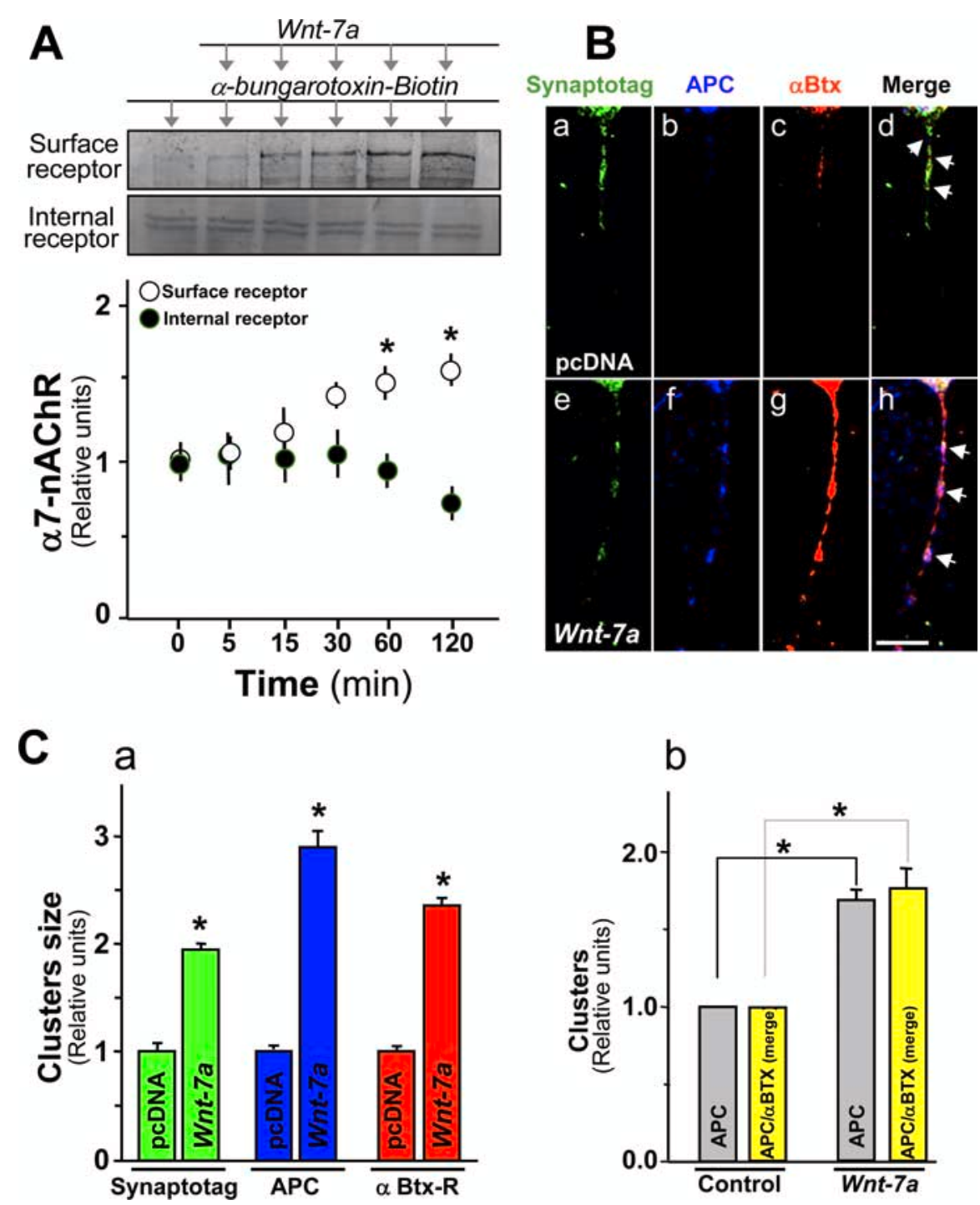

Figure 6. $\mathrm{APC}$ and $\alpha 7-\mathrm{nAChRs}$ are coclustered in presynaptic regions in hippocampal neurons exposed to Wnt-7a.A, Effects on surface $\alpha 7$-nAChR levels assessed using biotinylated- $\alpha$-Btx pull down and Western analysis in hippocampal neurons subjected to Wnt-7a treatments for different times show increases under conditions in which the fraction of $\alpha 7-\mathrm{nAChRs}$ in the intracellular pool also assessed by immunoblot decreases $(n=4)$. $\boldsymbol{B}$, Rhodamine-labeled $\alpha$-Btx fluorescence $(\boldsymbol{B C}, \boldsymbol{B g})$ or immunofluorescence for $A P C(B \boldsymbol{b}, \boldsymbol{B} \boldsymbol{f})$ or synaptotagmin (Synaptotag; $\boldsymbol{B} \boldsymbol{a}, \boldsymbol{B} \boldsymbol{e})$ in hippocampal neurons treated with control medium (pcDNA; $\boldsymbol{B a}-\boldsymbol{B} \boldsymbol{d}$ ) or Wnt-7a (Be-Bh) for $1 \mathrm{~h}$ indicates that Wnt-7a induces clustering of synaptotagmin $(\boldsymbol{B e}), \operatorname{APC}(\boldsymbol{B f})$, and $\alpha 7-n A C h R(B \boldsymbol{g})$. $\boldsymbol{B h}$, Arrows, Wnt-7a elevates coclustering of APC and $\alpha 7-n A C h R$ in presynaptic regions. Scale bar, $5 \mu \mathrm{m}$. C, Quantification of size for synaptotagmin (green bars), APC (blue bars), or $\alpha 7-n A C h R$ (identified by $\alpha$-Btx-R staining; red bars) clusters contained in neurites of hippocampal neurons ( $(\boldsymbol{a})$ and quantification of cluster numbers for APC and for APC contained in $\alpha$-Btx clusters (Cb). Data are the mean \pm SEM of five independent experiments. One hundred clusters per treatment per each independent experiment were evaluated using LSM 5 Image Browser.

fects of shorter-term exposure to Wnt-7a on interactions between $\mathrm{APC}$ and $\alpha 7$-nAChR and relocalization to the presynaptic terminal were not accompanied by effects on total levels of $\alpha 7$ nAChRs. However, prolonged activation of Wnt signaling after 12-24 h of treatment with Wnt-7a increased $\alpha 7$ subunit protein levels in an effect that began to reverse after $48 \mathrm{~h}$ of ligand exposure (data not shown). After $24 \mathrm{~h}$ of $W n t-7 a$ treatments, there was an increase to $\sim 1.7$-fold of control levels of nAChR $\alpha 7$ protein (Fig. 7Aa, $A b$ ). An induction of $\beta$-catenin levels indicated that the $W n t$ pathway remained activated at $24 \mathrm{~h}$ of $W n t-7 a$ exposure (Fig. $7 A a)$. Immunofluorescence assessments showed that hippocampal neurons treated with $W n t-7 a$ for $24 \mathrm{~h}$ had elevated expression of $\alpha 7$-nAChRs, mainly in neurites (Fig. $7 B a, B b$ ). Quantitative analysis indicated that the increase in the number of $\alpha 7$-nAChRs clusters was almost threefold (Fig. $7 B c$ ) and that there was an $\sim 80 \%$ increase in the size of each cluster (Fig. $7 B d$ ) under conditions in which the fluorescence intensity in the soma was not significantly altered by Wnt-7a treatment (data not shown). These results suggest that the nAChR $\alpha 7$ subunit is also a conventional target of canonical Wnt action.

\section{APC mediates $W n t-7 a$-induced} increases in $\alpha 7-n A C h R$ presynaptic clustering but not on $\mathrm{nAChR} \alpha 7$ subunit expression

To investigate roles of APC in short- and longer-term effects of Wnt-7a on clustering of APC and $\alpha 7-\mathrm{nAChR}$ in presynaptic terminals, we examined effects of siRNA knockdown of APC. Mouse hippocampal neurons were cotransfected at $10 \mathrm{~d}$ in vitro with APC siRNA or control (Ct) siRNA along with GFP protein to allow visualization of transfected neurons and their neurites. Two days later, neurons were exposed to $W n t-7 a$ for $24 \mathrm{~h}$, and rhodamine$\alpha$-Btx or anti-APC antibodies were used to label $\alpha 7$-nAChRs or APC, respectively. Transfection with the APC siRNA construct markedly suppressed APC levels in mouse hippocampal neurons (Fig. $8 A c, A$ $g, A k, A o)$. Neurons under control conditions (i.e., transfected in unconditioned medium with control siRNA; GFP/CtsiRNA) showed mainly a somatic localization of $\alpha 7$-nAChR and more weakly so in neurites (Fig. 8Aa,Ab). After treatment with $W n t-7 a$ for $24 \mathrm{~h}$, neurons transfected with control siRNA exhibited an increase in the neuritic localization of APC and $\alpha 7$ $\mathrm{nAChR}$ relative to cells treated with unconditioned medium controls (Fig. 8Ae$A h)$. Neurons transfected with APC siRNA under control conditions showed an increase in $\alpha 7$-nAChR levels relative to neurons transfected with control siRNA and also maintained in unconditioned medium (Fig. $8 A b, A j$ ), but this increase occurred in soma and not in neurites (Fig. $8 \mathrm{Aq}$ ). The increase in $\alpha 7$-nAChRs is consistent with the nAChR $\alpha 7$ subunit gene being a conventional Wnt target, knockdown of APC (implicated in the degradation of $\beta$-catenin) leading to $\beta$-catenin accumulation in the cytosol and its translocation to the nucleus, in which it induces Wnt target genes.

When hippocampal neurons were transfected with APC siRNA and treated with Wnt-7a ligand, $\alpha 7$-nAChR levels increased relative to levels in cells transfected with the same construct but maintained in unconditioned medium (Fig. $8 A j, A n$ ), but again $\alpha 7$-nAChRs were more highly expressed in soma (Fig. $8 A m, A n, A q)$. Complementary studies focusing on neuritic localization of APC and $\alpha 7$-nAChRs indicated that neurons transfected with APC siRNA do not have significant levels of neuritic 

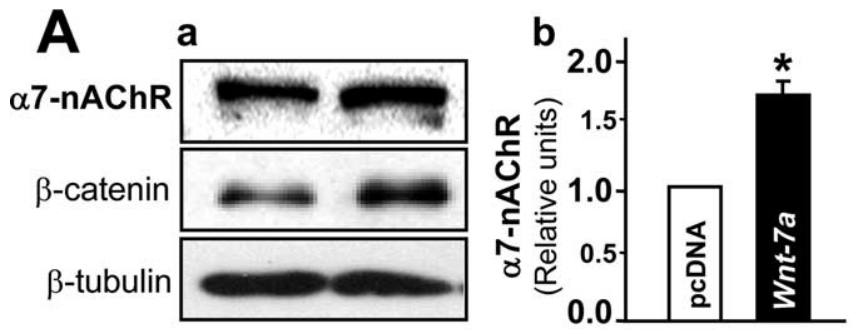

B
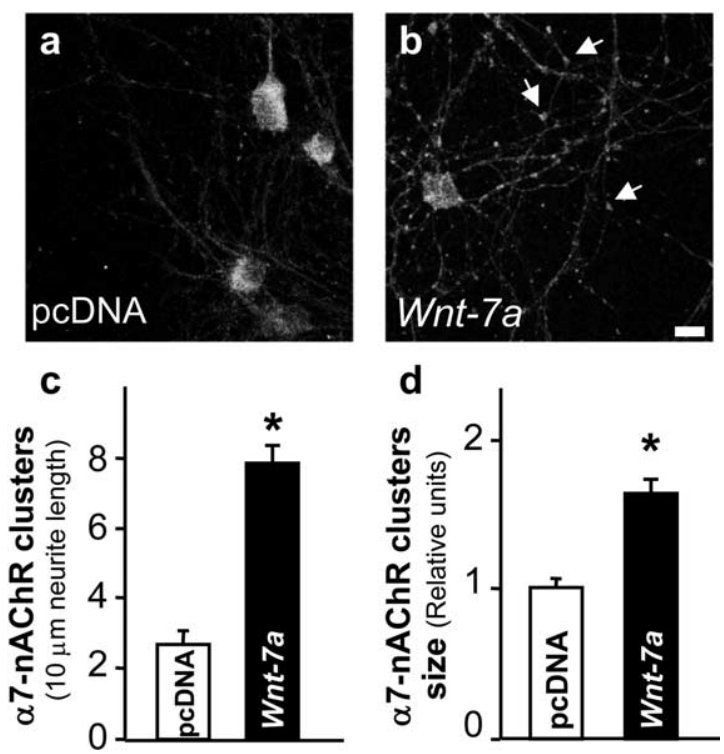

Figure 7. Wnt-7a increases $n A C h R \alpha 7$ subunit levels in hippocampal neurons. $A$, Western blot analysis of hippocampal neurons treated with Wnt-7a (right) or control (pcDNA; left) medium for $24 \mathrm{~h}$ was performed to assess effects on nAChR $\alpha 7$ subunit, $\beta$-catenin, or $\beta$-tubulin (normalization control) levels (Aa) and showed an increase in $\alpha 7$ subunit levels $(\boldsymbol{A} \boldsymbol{b} ; n=5)$. $\boldsymbol{B}$,

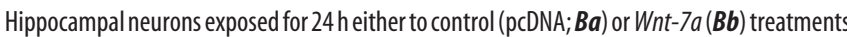
were analyzed using immunofluorescence to determine the distribution of total expressed $\alpha 7$-nAChRs. Wnt-7a treatment for $24 \mathrm{~h}$ induced preferential localization of $\alpha 7-\mathrm{nAChR}$ clusters in neurites (arrows). Scale bar, $10 \mu \mathrm{m}$. Bc, Quantification of $\alpha 7-n A C h R$ clusters per $10 \mu \mathrm{m}$ of neurite length shows that $W n t-7 a$ induces cluster formation in neurites. Data are the mean \pm SEM of four independent experiments. Bd, Quantification shows that Wnt-7a induces an increase in the size of clusters containing $\alpha 7-n A C h R$. Data are the mean \pm SEM of four independent experiments. One hundred clusters per treatment per each independent experiment were evaluated using LSM 5 Image Browser.

$\alpha 7$-nAChR or translocation of those sites to neurites after $W n t-7 a$ exposure, whereas receptor levels and their localization to neurites are higher under control conditions and increase with Wnt-7a exposure in neurons transfected with control siRNA (Fig. $8 B$ ). These results confirm the idea that $\alpha 7-n A C h R$ is a $W n t$ target, because APC knockdown is equivalent to persistent Wnt signaling as assessed by nAChR $\alpha 7$ subunit gene overexpression. Furthermore, these results suggest that APC plays a critical role in localizing $\alpha 7$-nAChR to presynaptic regions.

\section{Discussion}

$\mathrm{nAChR} \beta$ subunit-mediated interactions have been demonstrated between APC and the muscle-type receptor (Wang et al., 2003) and interactions between APC and nAChRs containing $\alpha 3$ subunits in ciliary ganglion neurons (Temburni et al., 2004). Here, we show that Wnt-7a induces specific interaction between $\alpha 7$-nAChRs and APC in rat hippocampal neurons. To our knowledge, this is the first evidence for the modulation of nAChR-APC interactions by canonical Wnt signaling.

$\alpha 7$-nAChRs have been identified at postsynaptic sites, at which they mediate classic, excitatory neurotransmission, perisynaptic sites, at which they exert a variety of modulatory effects, and presynaptic sites, at which they can modulate neurotransmitter release (Berg and Conroy, 2002). There is a wealth of information on $\alpha 7$-nAChRs in the presynaptic modulation of neurotransmitter release (Radcliffe and Dani, 1998; Alkondon and Albuquerque, 2001; Kawai et al., 2002). However, factors controlling the presynaptic localization of $\alpha 7-\mathrm{nAChRs}$ are not well understood.

The conventional effects of canonical Wnt signaling activation on different Wnt target genes are well known. Wnt signaling leads to stabilization and cytoplasmic accumulation of $\beta$-catenin, which is translocated to the nucleus, in which it activates the transcription of several Wnt target genes. There is no study to date, however, that reports on the early and late effects of Wnt signaling on target gene transcription in a specific system. The effects of Wnt signaling inhibition, however, have been studied using a variety of strategies such as in the presence of an excess of the Frizzled ligand binding domain, Dickkopf, through overexpression of axin, and via the activation of glycogen synthase kinase (van der Heyden et al., 1998; Lustig et al., 2002).

Here, we show that the canonical Wnt signaling affects $\alpha 7$ $n A C h R s$ in rodent hippocampal neurons in two ways: induction of $\alpha 7$-nAChR expression and relocalization of $\alpha 7-\mathrm{nAChR}$ to presynaptic sites. APC plays a role in $\alpha 7-\mathrm{nAChR}$ relocalization, because the process is disrupted in the presence of APC siRNA. This effect occurs despite the fact that knockdown of APC, which mimics activation of Wnt signaling by freeing $\beta$-catenin and thus allowing transcriptional consequences of Wnt pathway activation, produces an increase in $\mathrm{nAChR} \alpha 7$ subunits and, hence, total $\alpha 7$-nAChR levels. Thus, the nAChR $\alpha 7$ subunit gene could be another Wnt target. Interestingly, in silico analysis of the nAChR $\alpha 7$ subunit gene promoter reveals transcription binding sites for the Tcf-LEF/ $\beta$-catenin complex, although empirical evidence is needed to demonstrate the functionality of the site.

Recent studies have elucidated nonconventional roles of APC in the Wnt signaling pathway beyond its well understood role in regulating breakup of the $\beta$-catenin destruction complex. APC can associate with the cytoskeleton through its direct or indirect binding to microtubules (Dikovskaya et al., 2001). In neurons, APC has been shown to regulate the assembly of microtubules critical to axonal growth (Zhou et al., 2004) in a process that is inhibited by $\beta$-catenin (Votin et al., 2005). There is also indirect evidence of APC interactions with the actin cytoskeleton (Dikovskaya et al., 2001). Activation of Wnt signaling in carcinoma cells also induces the dissociation of APC from the $\beta$-catenin destruction complex and APC association with microtubules (Penman et al., 2005). Here, we found that APC dissociated from the $\beta$-catenin complex followed by its fast (minutes) association with membrane compartments and relocalization to MAP2a/bnegative, p-Tau-positive neurites corresponding to axons in Wnt-7a-treated hippocampal neurons. The magnitude of the increase in the number of APC clusters in neurites assessed using APC staining was higher than the magnitude calculated on the basis of axonal staining using colocalization with the anti-Tau antibody. However, because the AT- 8 antibody does not stain all axons uniformly, it is possible that there are some clusters of APC in some sections of axons that are AT- 8 negative. The functional consequences of APC in axons are clear in neuronal morphogenesis but still need to be defined in mature neurons.

In ciliary ganglion neurons, APC has been implicated in localization of $\alpha 3$-nAChRs to postsynaptic membranes (Temburni et al., 2004). However, in hippocampal neurons, APC colocalizes 
A
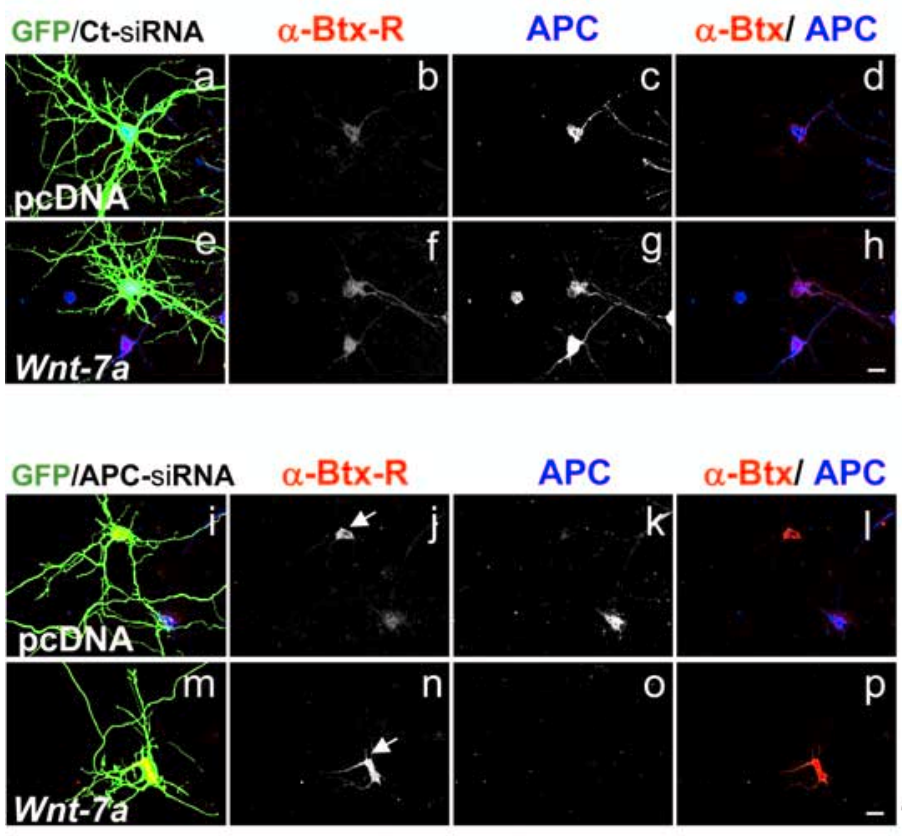

B
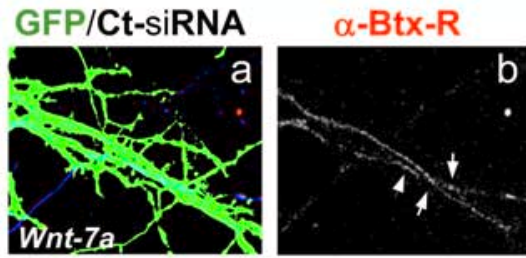

GFPIAPC-siRNA
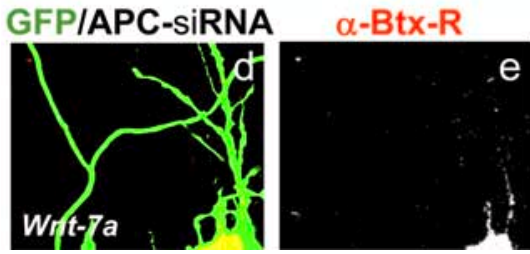

e
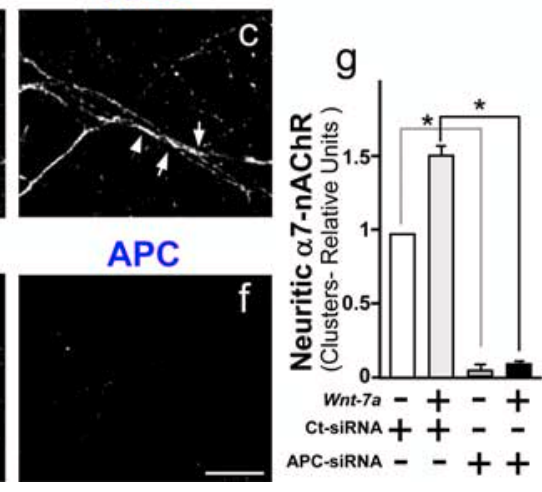

Figure 8. Wnt-7a treatment increases $n A C h R \alpha 7$ subunit levels in an APC-independent manner and alters the neuritic localization of $\alpha 7-n A C h R s$ in an APC-dependent manner. $\boldsymbol{A}$, Mouse hippocampal neurons cotransfected at $10 \mathrm{~d}$ in vitro with green fluorescent protein and control siRNA (GFP/Ct-siRNA; $\boldsymbol{A a}-\boldsymbol{A} \boldsymbol{h}$ ) or with GFP and anti-APC siRNA (GFP/APC-siRNA; $\boldsymbol{A i}-\boldsymbol{A p}$ ) were treated in the presence of control media (pcDNA; $\boldsymbol{A a}-\mathbf{A d}, \boldsymbol{A i}-\mathbf{A l})$ or Wnt-7a (Ae-Ah, $\boldsymbol{A m}-\mathbf{A p})$ for $24 \mathrm{~h}$ and were stained with rhodamine-labeled $\alpha$-Btx $(\alpha$-Btx-R; $\boldsymbol{A} \boldsymbol{b}, \boldsymbol{A f}, \boldsymbol{A j}, \boldsymbol{A n})$ or anti-APC (Ac, $\boldsymbol{A g}, \boldsymbol{A k}, \boldsymbol{A o})$. Arrows show regions of $\alpha$-Btx-R stain. GFP images were overexposed to visualize neurites. Scale bar, $10 \mu \mathrm{m}$. Aq, Somatic levels of $\alpha$ 7-nAChR staining. $\boldsymbol{B}$, Zoom images of Wnt-7a-treated (24 h) GFP/Ct-siRNA (Ba-Bc) or GFP/APC-siRNA ( $B \boldsymbol{d}-\boldsymbol{B} \boldsymbol{f}$ ) mouse hippocampal neurons stained with $\alpha$-Btx-R $(\boldsymbol{B} \boldsymbol{b}, \boldsymbol{B} \boldsymbol{e})$ or anti-APC $(\boldsymbol{B C}, \boldsymbol{B} \boldsymbol{f})$ as well as a quantitation of neuritic $\alpha 7-n A C h R$ clusters $(\boldsymbol{B g})$. Arrows show clusters of $\alpha 7-n A C h R$ and APC in control transfected neurons. Aq, Neurons transfected with APC siRNA show an increase in the soma of $\alpha$-Btx-R stain in the presence of control media relative to levels in neurons transfected with control siRNA, and Wnt-7a treatment induces an additional increase in somal $\alpha$-Btx-R staining in neurons transfected with APC siRNA but not in neurons transfected with control siRNA. Bg, In neurons transfected with inactive siRNA and exposed to Wnt-7a, an increase in the neuritic localization of $\alpha 7-\mathrm{nAChR}$ is observed relative to similarly transfected neurons in control media, but neuritic $\alpha 7-n A C h R s$ are very low and insensitive to Wnt treatment in APC-deficient cells. Data are the mean \pm SEM of three independent experiments performed in triplicate, expressed as fold increase over control cells.

with the presynaptic marker synaptotagmin (Matsumine et al., 1996). We did find an association between APC and the postsynaptic density protein, PSD-95, in hippocampal neurons, but Wnt-7a signaling did not increase coclustering of APC with PSD95, and closer observation revealed that there was apposition of APC and PSD-95 in synaptic regions but not colocalization at postsynaptic sites. It is possible that Wnt signaling through other

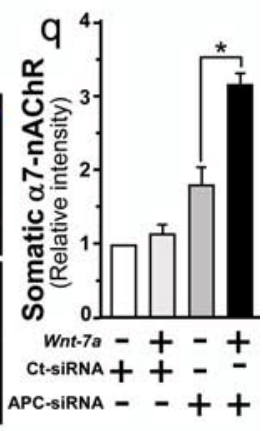

proteins regulates some components of the postsynaptic complex, perhaps differentially at excitatory or inhibitory synapses. However, Wnt-7a-mediated signaling-induced coclustering of APC with p-synapsin, SV-2, and synaptotagmin strongly implicates APC in regulation of presynaptic complexes in hippocampal neurons, thereby expanding the realm of possibilities regarding roles of APC in neuronal function.

Wnt signaling has been implicated in hippocampal neurogenesis (Lie et al., 2005) and in neurotransmitter release, the modulation of synaptic activity, and synaptogenesis in mossy fibers (AhmadAnnuar et al., 2006). Moreover, adult rat hippocampus and mature hippocampal neurons in culture express $W n t$ ligand, and we have observed that $W n t-7 a$ induces hippocampal neuronal synaptic vesicle exocytosis (Cerpa, Alfaro, Farias, Fuentealba, Metcalfe, Godoy, Bonansco, and Inestrosa, unpublished observations). Here, we demonstrate that Wnt-7a signaling induces the clustering of APC and $\alpha 7$ $\mathrm{nAChR}$ on mature neurons in presynaptic membranes as indicated by their cointeraction with SV-2, p-synapsin, VAMP-1/2, and synaptotagmin $1 \mathrm{a} / \mathrm{b}$. This suggests that Wnt-7a may dynamically modulate neurotransmitter release by altering $\alpha 7$ nAChRs levels at synaptic terminals, thereby contributing to synaptic plasticity. Wnt-7a exposure also affects the number and cluster size of several other essential, presynaptic proteins involved in neurotransmitter release, providing ways to affect synaptic function and plasticity in addition to or independent of effects on $\alpha 7$ nAChRs. APC plays an essential role in localization of $\alpha 7-\mathrm{nAChR}$ at the synapse, but there are some APC clusters that do not contain $\alpha 7$-nAChRs, so APC may also facilitate localization of other proteins to synapses at sites distinct from those at which $\alpha 7$-nAChRs cluster. Nevertheless, whether in maturing or mature neurons, $\alpha 7$-nAChRs could be an important synaptic target of Wnt signaling and/or an effector of the Wnt pathway.

Interestingly, whereas clusters of SV-2 or synaptotagmin containing $\alpha 7-\mathrm{nAChR}$ increased in size after $W n t-7 a$ exposure, the number of $\alpha 7$-nAChR/SV-2 coclusters decreased, suggesting that subtle processes are involved in $\alpha 7$-nAChR assembly, localization, and maintenance of position. Wnt ligands are a family of secreted glycoproteins encoded by a family of $\sim 20$ conserved genes in humans and other mammals (Moon et al., 2002), and we propose that different isoforms could be responsible for finer control of synaptic localization of $\alpha 7$-nAChRs.

$\mathrm{AD}$ is a neurodegenerative pathology characterized by an ex- 
tracellular accumulation of $\mathrm{A} \beta$ in the form of fibril aggregates that form senile plaques (Coyle et al., 1983; Selkoe, 2001; Palmer, 2002). The cholinergic impairment observed in AD patients is associated with a decrease in $\alpha 7$-nAChR levels (Banerjee et al., 2000) and a loss of synaptic contacts (Lacor et al., 2004). Therapies focused on the induction of cholinergic function for neuroprotection of $\mathrm{A} \beta$ have not been effective in $\mathrm{AD}$, possibly because of the decrease in $\alpha 7$-nAChRs in AD patients.

Neuronal death induced by $\mathrm{A} \beta$ in vitro can be prevented by exposure to canonical Wnt ligand (Alvarez et al., 2004), defects in Wnt signaling have been implicated in $\mathrm{AD}$ (De Ferrari and Inestrosa, 2000; Garrido et al., 2002; Caricasole et al., 2003; Fuentealba et al., 2004), and a loss of signaling through the $\beta$-cateninTCF pathway increases neuronal vulnerability to $A \beta$-induced apoptosis (Zhang et al., 1998). Recent evidence suggests that $\mathrm{A} \beta$ induces a deregulation of Wnt signaling components (De Ferrari et al., 2003; Alvarez et al., 2004; Farías et al., 2004; Quintanilla et al., 2005). However, the mechanisms by which Wnt signaling plays a role in $\mathrm{AD}$ pathology remain unclear. This is relevant in the context of the present work, because we found that $\alpha 7$ $\mathrm{nAChR}$ is a target of the Wnt pathway. Therapies aimed at activating Wnt signaling may possibly be effective in the treatment of $\mathrm{AD}$, especially if they prevent loss of $\alpha 7$-nAChRs and other important synaptic proteins.

In conclusion, the connection between $\alpha 7$-nAChRs and the Wnt pathway reported here provides new insights into the mechanisms relevant to maintenance of synaptic activity in health and disease.

\section{References}

Aberle H, Bauer A, Stappert J, Kispert A, Kemler R (1997) $\beta$-Catenin is a target for the ubiquitin-proteasome pathway. EMBO J 16:3797-3804.

Ahmad-Annuar A, Ciani L, Simeonidis I, Herreros J, Fredj NB, Rosso SB, Hall A, Brickley S, Salinas PC (2006) Signaling across the synapse: a role for Wnt and Dishevelled in presynaptic assembly and neurotransmitter release. J Cell Biol 174:127-139.

Alkondon M, Albuquerque EX (2001) Nicotinic acetylcholine receptors $\alpha 7$ and $\alpha 4 \beta 2$ subtypes differentially control GABAergic input to CA1 neurons in rat hippocampus. J Neurophysiol 86:3043-3055.

Alvarez AR, Godoy JA, Mullendorff K, Olivares GH, Bronfman M, Inestrosa NC (2004) Wnt-3a overcomes $\beta$-amyloid toxicity in rat hippocampal neurons. Exp Cell Res 297:186-196.

Banerjee C, Nyengaard JR, Wevers A, de Vos RA, Jansen Steur EN, Lindstrom J, Pilz K, Nowacki S, Bloch W, Schroder H (2000) Cellular expression of $\alpha 7$ nicotinic acetylcholine receptor protein in the temporal cortex in Alzheimer's and Parkinson's disease-a stereological approach. Neurobiol Dis 7:666-672.

Berg DK, Conroy WG (2002) Nicotinic $\alpha 7$ receptors: synaptic options and downstream signaling in neurons. J Neurobiol 53:512-523.

Borroni V, Baier CJ, Lang T, Bonini I, White MM, Garbus I, Barrantes FJ (2007) Cholesterol depletion activates rapid internalization of submicron-sized acetylcholine receptor domains at the cell membrane. Mol Membr Biol 24:1-15.

Brakeman JS, Gu SH, Wang XB, Dolin G, Baraban JM (1999) Neuronal localization of the adenomatous polyposis coli tumor suppressor protein. Neuroscience 91:661-672.

Cáceres A, Banker G, Steward O, Binder L, Payne M (1984) MAP2 is localized to the dendrites of hippocampal neurons which develop in culture. Brain Res 315:314-318.

Caricasole A, Copani A, Caruso A, Caraci F, Iacovelli L, Sortino MA, Terstappen GC, Nicoletti F (2003) The Wnt pathway, cell-cycle activation and $\beta$-amyloid: novel therapeutic strategies in Alzheimer's disease? Trends Pharmacol Sci 24:233-238.

Cong F, Schweizer L, Varmus H (2004) Casein kinase I epsilon modulates the signaling specificities of dishevelled. Mol Cell Biol 24:2000-2011.

Conroy WG, Berg DK (1998) Nicotinic receptor subtypes in the developing chick brain: appearance of a species containing the $\alpha 4, \beta 2$, and $\alpha 5$ gene products. Mol Pharmacol 53:392-401.
Coyle JT, Price DL, DeLong MR (1983) Alzheimer's disease: a disorder of cortical cholinergic innervation. Science 219:1184-1190.

De Ferrari GV, Inestrosa NC (2000) Wnt signaling function in Alzheimer's disease. Brain Res Brain Res Rev 33:1-12.

De Ferrari GV, Chacon MA, Barria MI, Garrido JL, Godoy JA, Olivares G, Reyes AE, Alvarez A, Bronfman M, Inestrosa NC (2003) Activation of Wnt signaling rescues neurodegeneration and behavioral impairments induced by beta-amyloid fibrils. Mol Psychiatry 8:195-208.

Dikovskaya D, Zumbrunn J, Penman GA, Nathke IS (2001) The adenomatous polyposis coli protein: in the limelight out at the edge. Trends Cell Biol 11:378-384

Fabian-Fine R, Skehel P, Errington ML, Davies HA, Sher E, Stewart MG, Fine A (2001) Ultrastructural distribution of the $\alpha 7$ nicotinic acetylcholine receptor subunit in rat hippocampus. J Neurosci 21:7993-8003.

Farías GG, Godoy JA, Hernandez F, Avila J, Fisher A, Inestrosa NC (2004) M1 muscarinic receptor activation protects neurons from $\beta$-amyloid toxicity. A role for Wnt signaling pathway. Neurobiol Dis 17:337-348.

Freedman R, Olincy A, Ross RG, Waldo MC, Stevens KE, Adler LE, Leonard S (2003) The genetics of sensory gating deficits in schizophrenia. Curr Psychiatry Rep 5:155-161.

Fuentealba RA, Farías G, Scheu J, Bronfman M, Marzolo MP, Inestrosa NC (2004) Signal transduction during amyloid- $\beta$-peptide neurotoxicity: role in Alzheimer disease. Brain Res Brain Res Rev 47:275-289.

Garrido JL, Godoy JA, Alvarez A, Bronfman M, Inestrosa NC (2002) Protein kinase $C$ inhibits $A \beta$ peptide neurotoxicity by acting on members of the Wnt pathway. FASEB J 16:1982-1984.

Gonzalez-Sancho JM, Brennan KR, Castelo-Soccio LA, Brown AM (2004) Wnt proteins induce dishevelled phosphorylation via an LRP5/6- independent mechanism, irrespective of their ability to stabilize beta-catenin. Mol Cell Biol 24:4757-4768.

Gray R, Rajan AS, Radcliffe KA, Yakehiro M, Dani JA (1996) Hippocampal synaptic transmission enhanced by low concentrations of nicotine. Nature 383:713-716.

Hall AC, Lucas FR, Salinas PC (2000) Axonal remodeling and synaptic differentiation in the cerebellum is regulated by WNT-7a signaling. Cell 100:525-535.

Herber DL, Severance EG, Cuevas J, Morgan D, Gordon MN (2004) Biochemical and histochemical evidence of nonspecific binding of $\alpha 7 \mathrm{nAChR}$ antibodies to mouse brain tissue. J Histochem Cytochem 52:1367-1376.

Kawai H, Zago W, Berg DK (2002) Nicotinic $\alpha 7$ receptor clusters on hippocampal GABAergic neurons: regulation by synaptic activity and neurotrophins. J Neurosci 22:7903-7912.

Kem WR (2000) The brain $\alpha 7$ nicotinic receptor may be an important therapeutic target for the treatment of Alzheimer's disease: studies with DMXBA (GTS-21). Behav Brain Res 113:169-181.

Kohrmann M, Haubensak W, Hemraj I, Kaether C, Lessmann VJ, Kiebler MA (1999) Fast, convenient, and effective method to transiently transfect primary hippocampal neurons. J Neurosci Res 58:831-835.

Lacor PN, Buniel MC, Chang L, Fernandez SJ, Gong Y, Viola KL, Lambert MP, Velasco PT, Bigio EH, Finch CE, Krafft GA, Klein WL (2004) Synaptic targeting by Alzheimer's-related amyloid $\beta$ oligomers. J Neurosci 24:10191-10200.

Levin ED, Simon BB (1998) Nicotinic acetylcholine involvement in cognitive function in animals. Psychopharmacology (Berl) 138:217-230.

Li Q, Lau A, Morris TJ, Guo L, Fordyce CB, Stanley EF (2004) A syntaxin 1, $\mathrm{G} \alpha_{\mathrm{o}}$, and N-type calcium channel complex at a presynaptic nerve terminal: analysis by quantitative immunocolocalization. J Neurosci 24:4070-4081.

Lie DC, Colamarino SA, Song HJ, Desire L, Mira H, Consiglio A, Lein ES, Jessberger S, Lansford H, Dearie AR, Gage FH (2005) Wnt signalling regulates adult hippocampal neurogenesis. Nature 437:1370-1375.

Lustig B, Jerchow B, Sachs M, Weiler S, Pietsch T, Karsten U, van de Wetering M, Clevers H, Schlag PM, Birchmeier W, Behrens J (2002) Negative feedback loop of Wnt signaling through upregulation of conductin/axin2 in colorectal and liver tumors. Mol Cell Biol 22:1184-1193.

Manders EEM, Verbeek FJ, Aten JA (1993) Measurement of co-localization of objects in dual-colour confocal images. J Microsc 169:375-382.

Matsumine A, Ogai A, Senda T, Okumura N, Satoh K, Baeg GH, Kawahara T, Kobayashi S, Okada M, Toyoshima K, Akiyama T (1996) Binding of APC to the human homolog of the Drosophila discs large tumor suppressor protein. Science 272:1020-1023. 
Moon RT, Bowerman B, Boutros M, Perrimon N (2002) The promise and perils of Wnt signaling through $\beta$-catenin. Science 296:1644-1646.

Moon RT, Kohn AD, De Ferrari GV, Kaykas A (2004) Wht and $\beta$-catenin signalling: diseases and therapies. Nat Rev Genet 5:691-701.

Nusse R, Varmus HE (1992) Wnt genes. Cell 69:1073-1087.

Palmer AM (2002) Pharmacotherapy for Alzheimer's disease: progress and prospects. Trends Pharmacol Sci 23:426-433.

Patapoutian A, Reichardt LF (2000) Roles of Wnt proteins in neural development and maintenance. Curr Opin Neurobiol 10:392-399.

Penman GA, Leung L, Näthke IS (2005) The adenomatous polyposis coli protein (APC) exists in two distinct soluble complexes with different functions. J Cell Sci 118:4741-4750.

Quintanilla RA, Munoz FJ, Metcalfe MJ, Hitschfeld M, Olivares G, Godoy JA, Inestrosa NC (2005) Trolox and $17 \beta$-estradiol protect against amyloid $\beta$-peptide neurotoxicity by a mechanism that involves modulation of the Wnt signaling pathway. J Biol Chem 280:11615-11625.

Radcliffe KA, Dani JA (1998) Nicotinic stimulation produces multiple forms of increased glutamatergic synaptic transmission. J Neurosci 18:7075-7083.

Role LW, Berg DK (1996) Nicotinic receptors in the development and modulation of CNS synapses. Neuron 16:1077-1085.

Rosso SB, Sussman D, Wynshaw-Boris A, Salinas PC (2004) Wnt signaling through Dishevelled, Rac and JNK regulates dendritic development. Nat Neurosci 8:34-42.

Schulte G, Bryja V, Rawal N, Castelo-Branco G, Sousa KM, Arenas E (2005) Purified Wnt-5a increases differentiation of midbrain dopaminergic cells and dishevelled phosphorylation. J Neurochem 92:1550-1553.

Seto ES, Bellen HJ (2006) Internalization is required for proper Wingless signaling in Drosophila melanogaster. J Cell Biol 173:95-106.

Selkoe DJ (2001) Alzheimer's disease: genes, proteins, and therapy. Physiol Rev 81:741-766.
Sheng M (2001) Molecular organization of the postsynaptic specialization. Proc Natl Acad Sci USA 98:7058-7061.

Sytnyk V, Leshchyns'ka I, Dityatev A, Schachner M (2004) Trans-Golgi network delivery of synaptic proteins in synaptogenesis. J Cell Sci 117:381-388.

Temburni MK, Rosenberg MM, Pathak N, McConnell R, Jacob MH (2004) Neuronal nicotinic synapse assembly requires the adenomatous polyposis coli tumor suppressor protein. J Neurosci 24:6776-6784.

Vernino S, Amador M, Luetje CW, Patrick J, Dani JA (1992) Calcium modulation and high calcium permeability of neuronal nicotinic acetylcholine receptors. Neuron 8:127-134.

Votin V, Nelson WJ, Barth AI (2005) Neurite outgrowth involves adenomatous polyposis coli protein and $\beta$-catenin. J Cell Sci 118:5699-5708.

Wang J, Jing Z, Zhang L, Zhou G, Braun J, Yao Y, Wang ZZ (2003) Regulation of acetylcholine receptor clustering by the tumor suppressor APC. Nat Neurosci 6:1017-1018.

Zago WM, Massey KA, Berg DK (2006) Nicotinic activity stabilizes convergence of nicotinic and GABAergic synapses on filopodia of hippocampal interneurons. Mol Cell Neurosci 31:549-559.

Zhang Z, Hartmann H, Do VM, Abramowski D, Sturchler-Pierrat C, Staufenbiel M, et al (1998) Destabilization of $\beta$-catenin by mutations in presenilin-1 potentiates neuronal apoptosis. Nature 395:698-702.

Zhao L, Kuo YP, George AA, Peng JH, Purandare MS, Schroeder KM, Lukas RJ, Wu J (2003) Functional properties of homomeric, human $\alpha_{7^{-}}$ nicotinic acetylcholine receptors heterologously expressed in the SH-EP1 human epithelial cell line. J Pharmacol Exp Ther 305:1132-1141.

Zhou FQ, Zhou J, Dedhar S, Wu YH, Snider WD (2004) NGF-induced axon growth is mediated by localized inactivation of GSK-3beta and functions of the microtubule plus end binding protein APC. Neuron 42:897-912. 